Ozone: Science \& Engineering

The Journal of the International Ozone Association

\title{
A Review on the Applications of Ozonation for the Treatment of Real Agro-Industrial Wastewaters
}

\author{
Rui C. Martins \& Rosa M. Quinta-Ferreira
}

To cite this article: Rui C. Martins \& Rosa M. Quinta-Ferreira (2014) A Review on the Applications of Ozonation for the Treatment of Real Agro-Industrial Wastewaters, Ozone: Science \&

Engineering, 36:1, 3-35, DOI: 10.1080/01919512.2013.842158

To link to this article: https://doi.org/10.1080/01919512.2013.842158

Accepted author version posted online: 21

Nov 2013.

Published online: 21 Nov 2013.

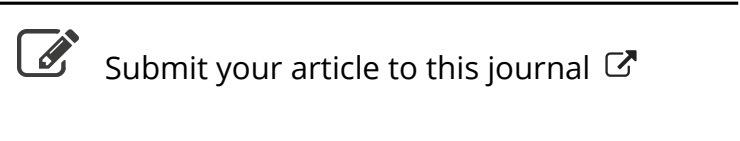

Џ Article views: 373

View Crossmark data ¿

Citing articles: 7 View citing articles $\longleftarrow$ 


\title{
A Review on the Applications of Ozonation for the Treatment of Real Agro-Industrial Wastewaters
}

\author{
Rui C. Martins and Rosa M. Quinta-Ferreira
}

CIEPQPF (Chemical Process Engineering and Forest Products Research Centre), GERSE (Group on Environment, Reaction and Separation Engineering), Department of Chemical Engineering, Faculty of Sciences and Technology, University of Coimbra, Pólo II, 3030-790 Coimbra, Portugal

\begin{abstract}
Regarding agro-wastewaters, the strong loads in biorefractory substances and seasonality reduce the efficiency of biological treatments and ozonation can play an important role, so that this article reviews its application for such streams. Indeed, biodegradability and toxicity removal was assessed for a wide range of agro-effluents such as olive mill, wineries and distilleries, pulp and paper, cork and cheese production. Solid catalysts reveal promising potential, even though literature is still scarce reporting their use to actual streams. Thus, forthcoming research must embrace catalytic ozonation and continuous pilot-scale reactors behavior on the depuration of real agro-wastewaters to ensure future industrial application.
\end{abstract}

Keywords Ozone, Ozonation, Agro-industrial Wastewaters, Biodegradability Enhancement, Heterogeneous Catalysis, Toxicity

\section{INTRODUCTION}

The decrease in fresh water quantity and quality is one of the major social, technological, economical, and political problems of our days. Indeed, the access to secure water provisions, hygienic sanitation and suitable waste management are crucial to health, allowing preventing almost one tenth of global diseases such as diarrhea and malaria, according to the world health organization (WHO). If the diminishing of utilizable water in developing countries is mainly due to economical or climatic issues, in developed countries the increase in industrial and domestic activities generate a wide diversity of polluted effluents which, when discharged in natural water

Received 4/8/2013; Accepted 8/2/2013

Address correspondence to Rui C. Martins, Department of Chemical Engineering, Faculty of Sciences and Technology, University of Coimbra, Pólo II, Rua Sílvio Lima, 3030-790 Coimbra, Portugal.E-mail: martins@eq.uc.pt courses, cause a disastrous effect in surroundings (Pera-Titus et al. 2004).

Therefore, legislation around the world has become more restrictive concerning environmental regulations and health quality standards. The European Parliament, reflecting a new ecological conscience, established a Community framework (European directive 2000/60/CE) for water protection and management, ascertaining different uses and highlighting the necessity to implement solutions against its contamination aiming to lessen pollutants progressively.

Within this context, environment protection by reducing and treating the effluents is a major defy to stakeholders since industrial activities can be seriously threatened if the environmental laws are not accomplished. Researchers have, thus, the duty of providing them with the most suitable technological solutions for each specific case. The traditional biological treatment systems present unsatisfactory results when applied to the degradation of wastewaters encompassing large fractions of bio-refractory compounds (such as the effluents coming from agro-food processing industries) and the development of chemical oxidation strategies is then required.

In this ambit, ozonation has been widely studied in the last decades for wastewater treatment due to its potential in oxidizing organic matter and disinfection (Pera-Titus et al. 2004), (Gogate and Pandit 2004a; Gogate and Pandit 2004b). Ozone is a powerful oxidant compound $\left(\mathrm{E}^{\circ}=2.07 \mathrm{~V}\right)$ able to react with several chemical species at ambient conditions of pressure and temperature. Ozone disinfectant properties have been well known since the beginning of the century; nevertheless, recently it has received much attention as a water treatment technology being applied to improve taste and color as well as to remove organic and inorganic compounds (Kasprzyk-Hordern et al. 2003).

In single ozonation (without catalyst), ozone presents a double action over the pollutants according to the medium $\mathrm{pH}$. At low $\mathrm{pH}$ values $(\mathrm{pH}<4)$, ozone reacts selectively with 
compounds comprising high electronic density sites such as chromophores groups and unsaturated bonds (direct pathway). Contrarily, for alkaline conditions $(\mathrm{pH}>9)$ hydroxide ions promote the molecular ozone decomposition into hydroxyl radicals capable to decompose a wider range of organic pollutants (free radical pathway). For $\mathrm{pH}$ within 4-9, both pathways are present (Staehelin and Hoigne 1982). Ozone decomposition in water can be also endorsed by UV radiation and hydrogen peroxide (Staehelin and Hoigne 1982); (Gogate and Pandit 2004a; Gogate and Pandit 2004b).

Ozonation alone generally reaches low mineralization levels since the low molecular weight carboxylic acids produced during the depuration process are refractory to further ozone oxidation. As a consequence, significant research efforts have been made to improve ozone action over pollutants by the addition of homogeneous or heterogeneous catalysts promoting either hydroxyl radicals production or enhancing molecular ozone reactions (Kasprzyk-Hordern et al. 2003; Legube and Karpel Vel Leitner 1999; Martins and Quinta-Ferreira 2009; Martins and Quinta-Ferreira 2011a; Nawrocki and Kasprzyk-Hordern 2010). The use of heterogeneous catalysis rather than homogeneous is advantageous since it is easier to retrieve the solid catalyst from the reaction media. Therefore, the seeking for an active and stable catalyst for environmental purposes is an important task and intensive studies have been recently made in this realm.

Heterogeneous catalytic ozonation can follow different mechanisms, recently reviewed by (Nawrocki and KasprzykHordern 2010), depending on the catalyst and pollutants involved, which difficult generalizations regarding the pathway of this process. If some authors refer hydroxyl radicals formation from the catalytic decomposition of ozone over the solid (Ma and Graham 2000; Sánchez-Polo et al. 2006), different conclusions were taken, for example, in the work by (Ma et al. 2005) where those radicals were not identified as the main responsible of the nitrobenzene catalytic ozonation over $\mathrm{MnOx} / \mathrm{GAC}$. In fact, our recent results pointed out diverse mechanisms on simulated olive mill wastewater degradation by catalytic ozonation at the same operating conditions while applying different catalysts.

When the laboratory Mn-Ce-O 70/30 was used, treatment was mainly due to surface reactions involving both pollutants and ozone adsorption on the solid (Martins and Quinta-Ferreira 2009). Contrarily, the commercial $\mathrm{Fe}_{2} \mathrm{O}_{3}$ $\mathrm{MnO}_{\mathrm{x}}(\mathrm{N}-150)$ promoted $\mathrm{O}_{3}$ decomposition into hydroxyl radicals (Martins and Quinta-Ferreira 2011b). Indeed, the treatment efficiency for catalytic ozonation over Mn-Ce-O $70 / 30$ showed to be independent of the presence of radical scavengers in solution whereas for $\mathrm{Fe}_{2} \mathrm{O}_{3}-\mathrm{MnO}_{\mathrm{x}}(\mathrm{N}-150)$ a decrease on effectiveness was observed when carbonates or tert-butanol were added indicating the presence of the hydroxyl radicals.

Bearing in mind the scientific challenge of proposing suitable treatment schemes for agro-industrial wastewaters and the potential of ozone in this ambit, the aim of this review paper is to overview and discuss the main results found in literature regarding the application of ozonation on the depuration of real agro-effluents. The use of solid catalysts to enhance ozone action and the integration of this chemical process with traditional biological systems will be highlighted. In this ambit, for each case, single processes are firstly addressed, followed by the possible use of co-oxidant promoters (light and $\mathrm{H}_{2} \mathrm{O}_{2}$ ), integration strategies and catalytic operation results. Trying to shade light to the path to be followed in this area, the main questions that still needed to be answered so that this technology can be industrially spread will be emphasized.

\section{APPLICATION OF OZONATION TO AGRO-INDUSTRIAL WASTEWATERS}

Agro-industries, generally encompassing food processing, pulp and paper and cork production, represent a vital economical branch in most countries. These plants usually consume large amounts of processing water leading to huge volumes of polluted wastewater involving complex chemical compositions that constitute a serious environmental danger if directly disposed into the natural water streams. Moreover, in some cases, the seasonal character of these activities impart sharp variations in both effluents' flow and composition which reduce the applicability of biological depuration systems to minimize the pollutant impact of such wastewaters. Besides, these streams present some bio-refractory and toxic compounds such as aromatic substances that disturb both aerobic and anaerobic reactors.

In this context, the use of chemical oxidation strategies seems to be required to fulfill the strict environmental legislation for discharge throughout the local water courses. Ozonation appears as a suitable option for these cumbersome flows and its application has been widely studied in the last years for the degradation of model compounds (e.g., Faria et al. 2009; He et al. 2008; Larcher et al. 2012; Moussavi et al. 2009) and synthetic mixtures (Carbajo et al. 2006; Martins and Quinta-Ferreira 2011b). However some research has been performed regarding the abatement of real effluents and aiming to highlight the potential of this technology for the treatment of actual agro-industrial wastewaters this article reviews the investigation carried out in this ambit.

\section{Olive Processing Wastewater}

Olive oil extraction and table olive preparation constitutes an important economic activity in most of Mediterranean countries (Mantzavinos and Kalogerakis 2005). For example, according to the Portuguese statistics institute (INE), 420 million ton of olives were produced in Portugal in 2010.

The commonly called olive mill wastewater (OMW) is generated from olives milling and centrifugation to obtain the oily juice, whereas the effluent generated by the table olives preparation is due to the stream used for the fruits treatment in order to remove its bitterness (usually it is applied a 
$2 \%$ sodium hydroxide solution) (Bautista et al. 2008). These liquid wastes are known by their high organic loading (up to $220 \mathrm{~g} / \mathrm{L}$ in chemical oxygen demand) encompassing a large amount of fats, polyphenols and volatile organic acids (Azbar et al. 2004) with bio refractory and toxic levels. Moreover, the characteristics of the streams are highly variable depending upon climatic conditions, olive cultivates, fruit maturation and type of extraction (Gomec et al. 2007), making difficult the acclimation of bio-reactors, reducing thus the efficiency of such depuration systems.

Table 1 summarizes the published works regarding the application of ozonation on the treatment of actual olive industry effluents.

\section{Single Ozonation}

The most usual way to manage these wastewaters consists in dumping them in evaporation pounds (Karageorgos et al. 2006), which are an environmental danger for groundwater besides the production of bad smells (Azbar et al. 2004). Moreover, this process depends upon the weather conditions. It means that the effluent may not evaporate by the end of the summer and the pond may not be available in the next year. Karageorgos et al. (2006) analyzed this possibility and investigated the potential of ozonation on the management of such weathered effluents (Table 1). Ozone was able to remove up to $80 \%$ of phenolic content (TPh) and color in $120 \mathrm{~min}$ of reaction. However, organic matter mineralization was very low pointing out that ozone selectively attacks (ozonolysis) compounds encompassing multiple bounds or specific functional groups characterized by high electronic density. In fact, COD removal was mainly due to TPh abatement. The high $\mathrm{TPh}$ removal efficiency truly decreased the effluents toxicity over vibrio fischery.

Molecular ozone by itself is usually very efficient when the aim is the degradation of compounds prone to suffer electrophilic attack (such as phenols). However, from the degradation of those molecules, low molecular weight byproducts (such as carboxylic acids) no further reactive with ozone are produced, leading, thus, to low mineralization efficiencies. Besides, an important technological issue of this technology is related with ozone mass transfer being required a proper gas/liquid contactor design. Chedaville et al. (2009) applied single ozonation $(\mathrm{pH}=5)$ for the depuration of OMW proposing an ejector as gas/liquid contactor which enhanced ozone mass transfer ratio to $95 \%$. However, even if up to $80 \%$ of TPh removal was attained only $48 \%$ of COD degradation was possible in 40 min leading to a final stream still with about $3.4 \mathrm{gO}_{2} / \mathrm{L}$ much above the legal limit of $150 \mathrm{mgO}_{2} / \mathrm{L}$ for direct discharge to the natural water courses being proposed its disposal into a classical wastewater treatment plant for further management.

$\mathrm{pH}$ is a key factor in ozonation, ozone is known by its double action over the pollutants which can be through direct molecular attack (direct pathway) that mainly occurs at low $\mathrm{pH}$ values or by indirect reactions involving ozone decomposition into hydroxyl radicals which unselectively react with a wide range of compounds (radical pathway) enhanced by alkaline conditions. Thus, Rivas et al. (2000a) analyzed the possibility of enhancing ozonation action over table olive wastewater (TOW) and olive oil mill wastewater (OMW) by the application of different acidic and basic cycles during the process. The aim of the investigation was to joint the advantages of both mechanisms and it was concluded that the application of sequential acid and alkaline stages increased COD removal when compared to the values attained when ozonation was carried out in a nonsequential way.

Moreover, the best results were observed when the treatment started at $\mathrm{pH} 4$ (for $20 \mathrm{~min}$ ) followed by an alkaline stage (pH 10) with COD abatement of about $99 \%$. This enhancement was attributed to the best use of the ozone. In fact, in the first stage, the substances reactive with molecular ozone were degraded and in a second phase $\mathrm{pH}$ is raised promoting the production of hydroxyl radicals, which are reactive with the remaining organic compounds refractory to ozone. In addition, an increase on the effluents biodegradability in more than $100 \%$ (measured by the ratio $\mathrm{BOD}_{5} / \mathrm{COD}$ ) was observed when $\mathrm{pH}$ was sequentially changed along the reaction contrarily to the case where $\mathrm{pH}$ was kept unchanged actually leading to a slight $\mathrm{BOD}_{5} / \mathrm{COD}$ decrease. The final results pointed out that it would be possible to implement an aerobic biological system afterwards to further refine the wastewater. In order to minimize operating costs with the addition of mineral acids or bases to change $\mathrm{pH}$, the authors propose the joint treatment of TOW (typically an alkaline stream) and OMW (generally acidic) as an alternative way to endorse $\mathrm{pH}$ variations during the process.

\section{Ozonation Aided by Light and/or Hydrogen Peroxide}

The results attained by Rivas et al. (2000b) reveal the potential of promoting hydroxyl radicals production that may be accomplished at alkaline conditions or by using ozonation aided by $\mathrm{H}_{2} \mathrm{O}_{2}$ or UV radiation. A synergetic effect was detected between ozone and hydrogen peroxide leading to a high improvement in what regards the COD abatement of debbitering table olive wastewater (Beltrán et al. 1999). In fact, while $\mathrm{O}_{3}$ reached about $50 \%$ of COD removal, the application of ozone aided by hydrogen peroxide $\left(10^{-3} \mathrm{M}\right)$ was able to degrade up to $80 \%$ of the initial COD.

Furthermore, the use of ozone with low concentrations of hydrogen peroxide favored the effluents $\mathrm{BOD}_{5} / \mathrm{COD}$ enabling then a further aerobic digestion. Similar results were attained when UV $\left(5.26 \times 10^{-6}\right.$ Einstein/s $)$ was coupled with ozonation promoting up to $75 \%$ of COD depletion besides an improvement on the wastewater biodegradability. It seems then that those chemical methodologies should be used prior to aerobic biological treatments to promote a previous removal of bio-refractory and toxic compounds.

Benitez et al. (2001) verified an increase of up to $90 \%$ of COD removal and an improvement of biodegradability with $\mathrm{BOD}_{5} / \mathrm{COD}$ raising from 0.55 to up to 0.96 when ozonation 


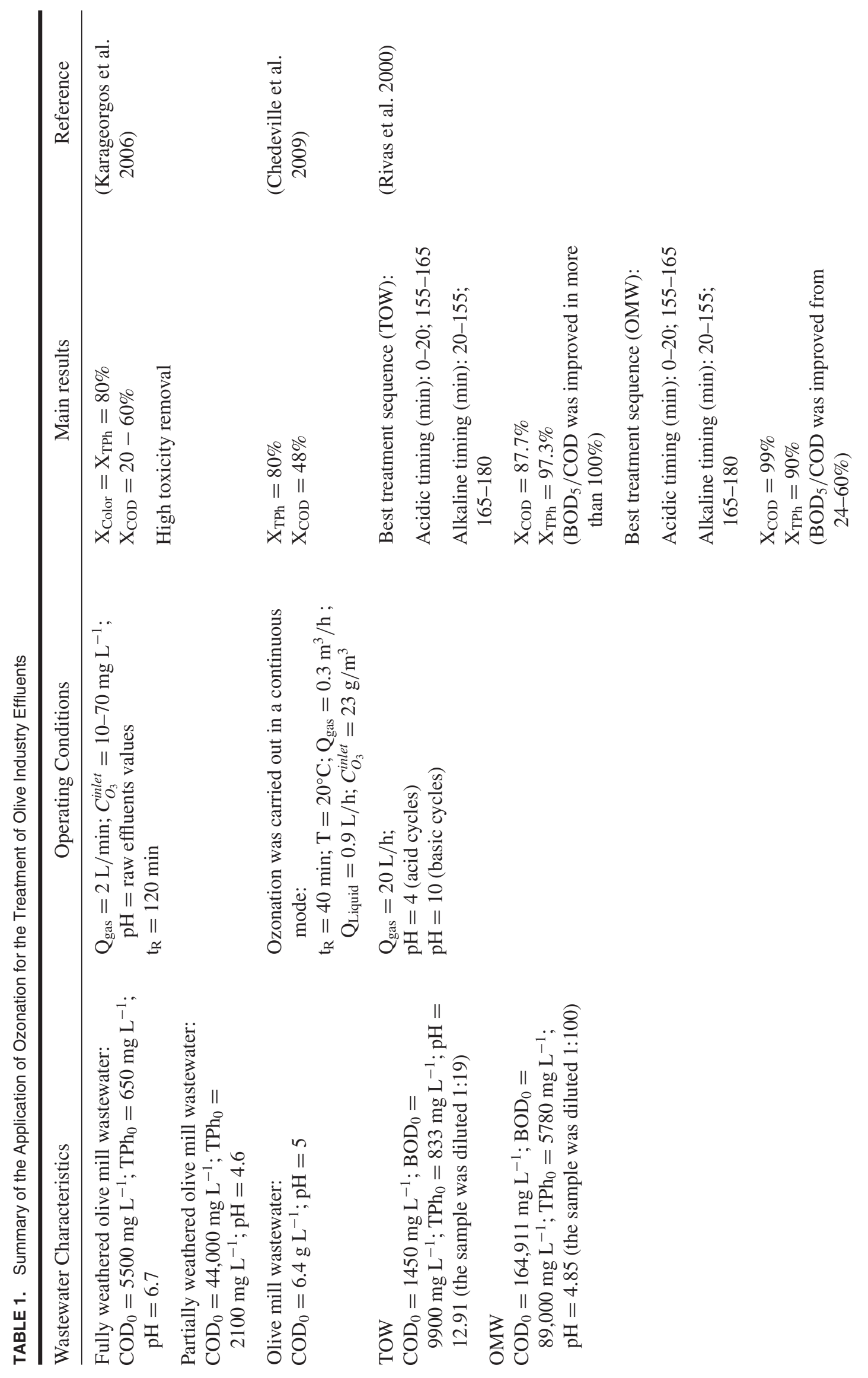



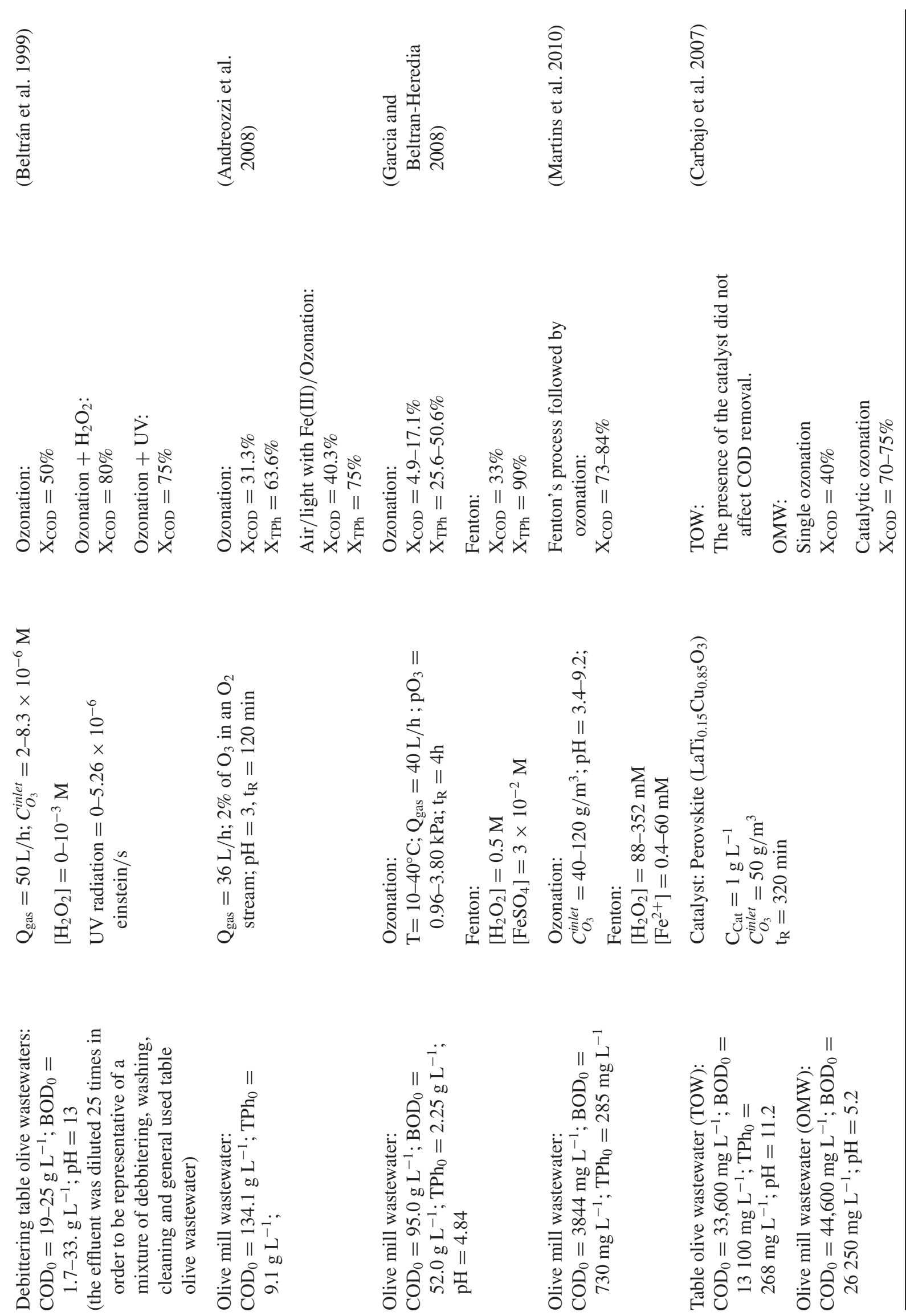


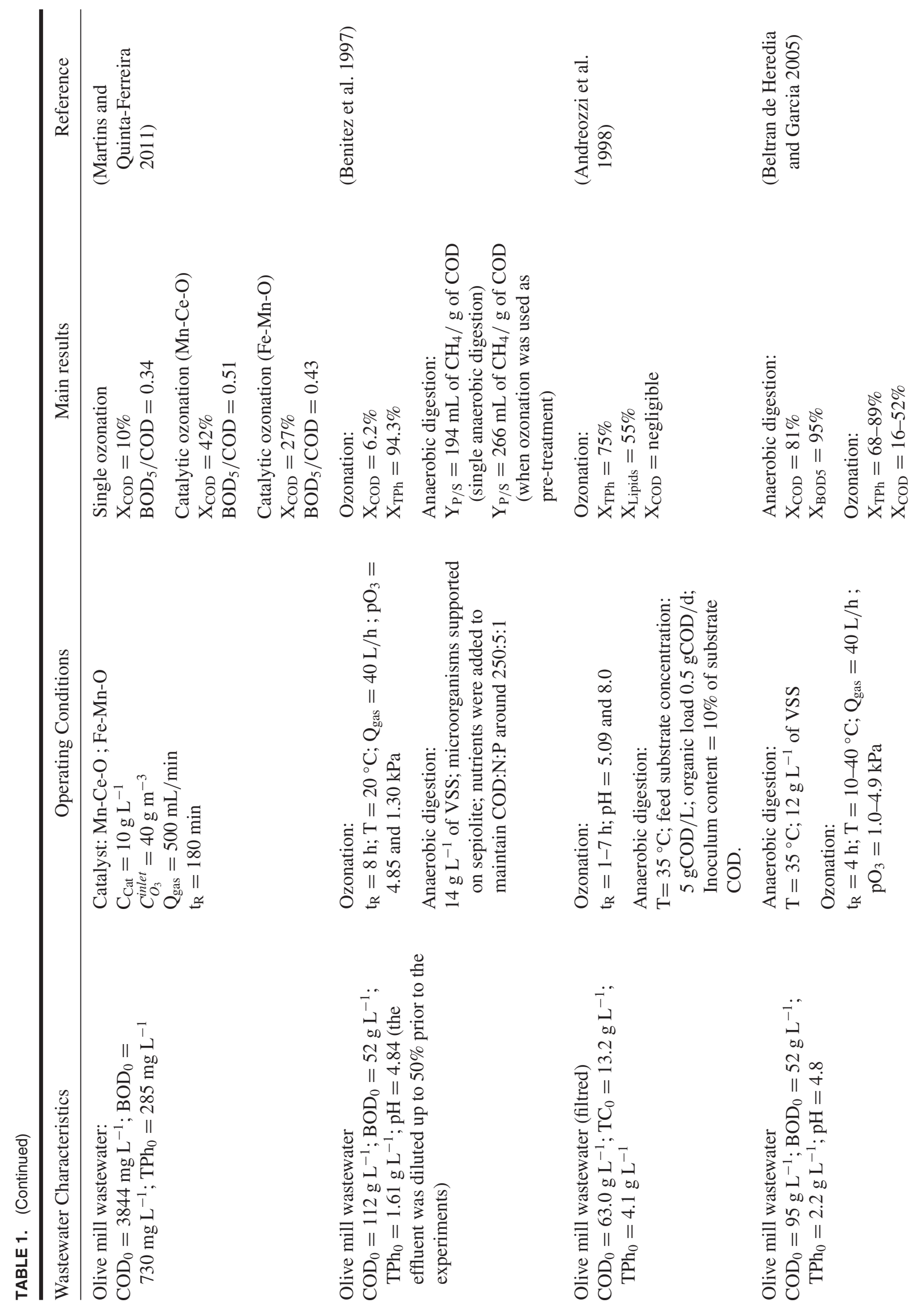



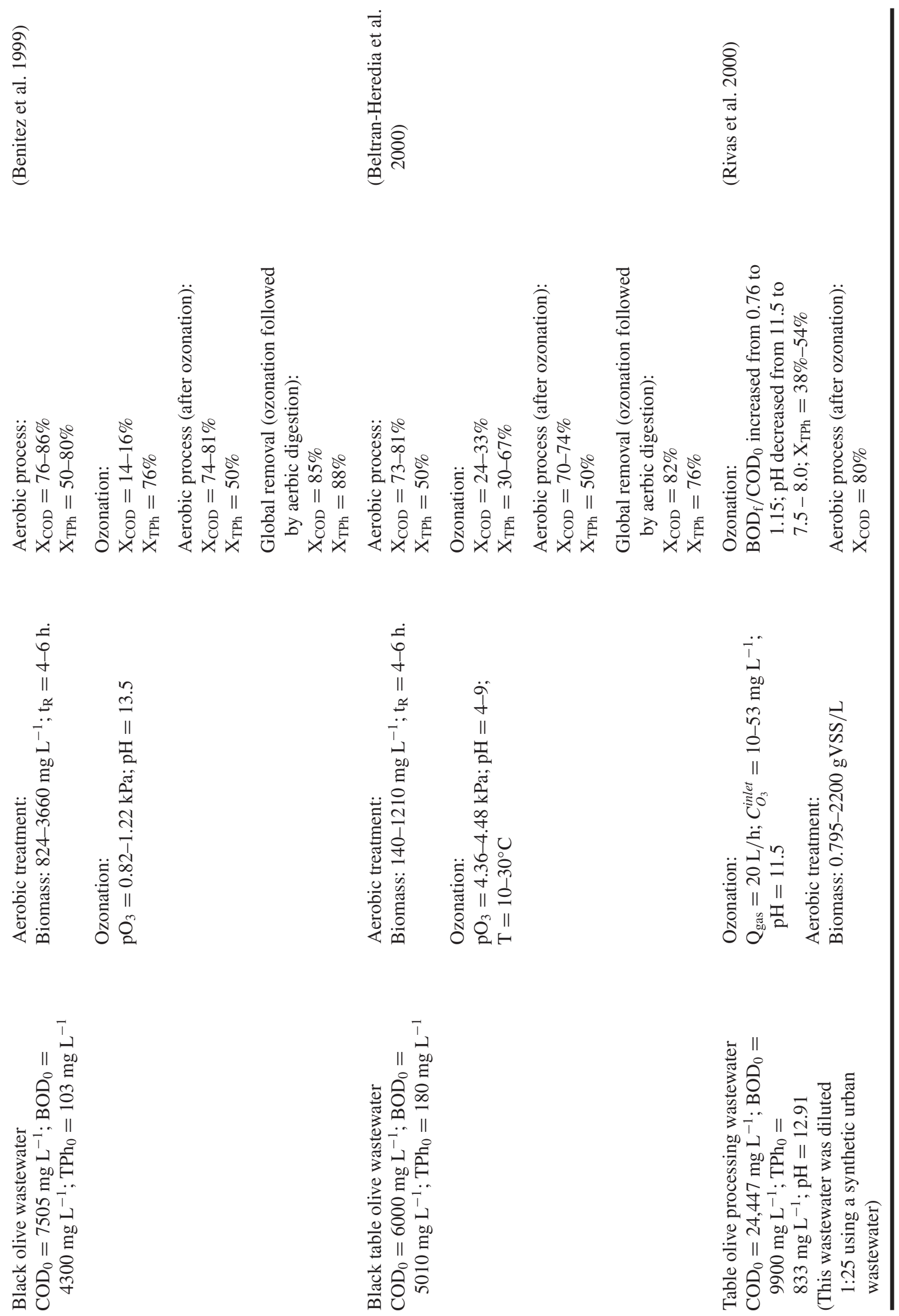


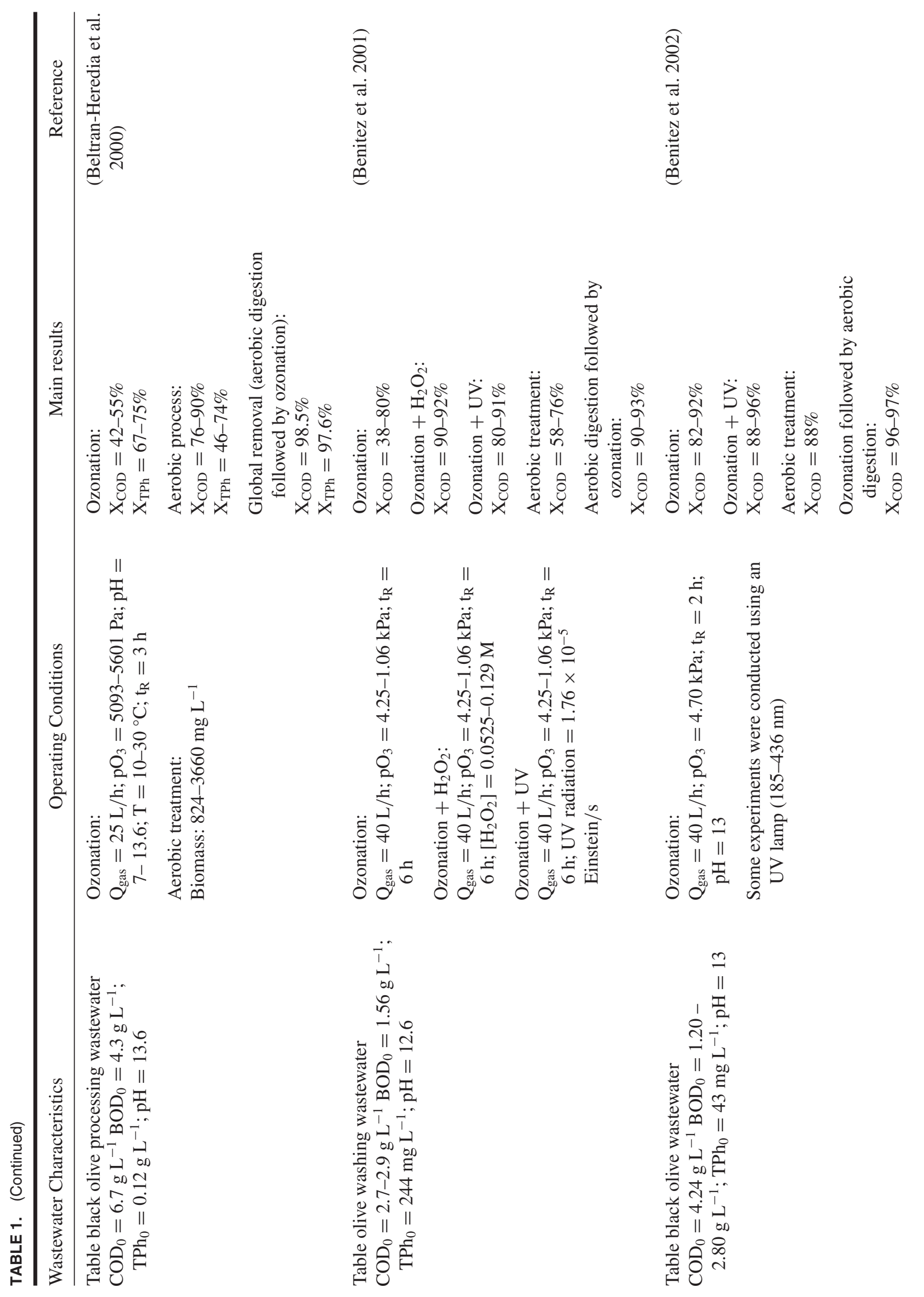




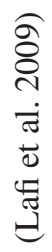
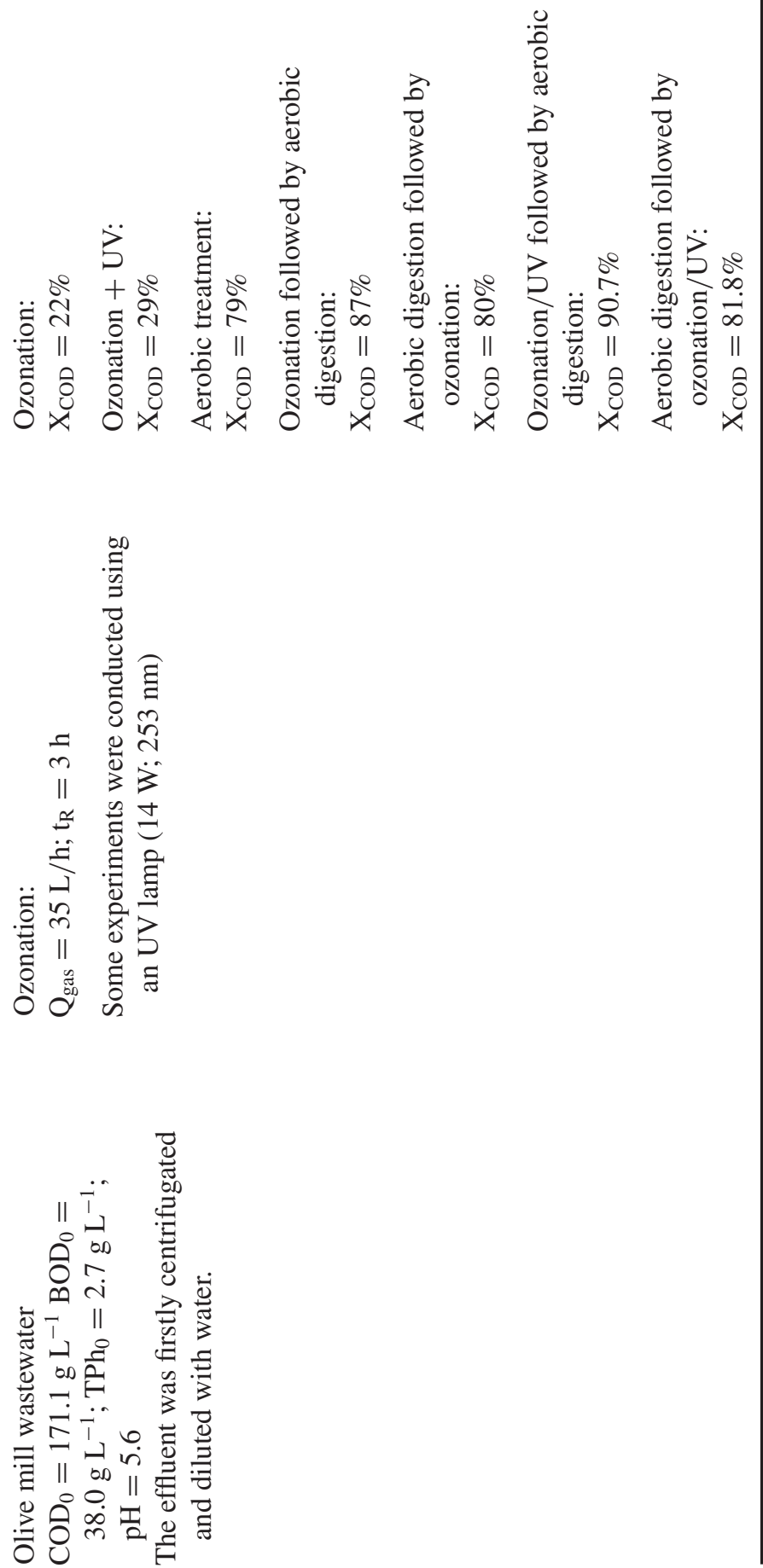
was combined with hydrogen peroxide $(0.0525-0.129 \mathrm{M})$ or with UV radiation. Besides, a $\mathrm{pH}$ decrease from 12.6 to 8.29 was detected which, allied with the $\mathrm{BOD}_{5} / \mathrm{COD}$ increase, is favorable for the application of a subsequent activated sludge reactor. Moreover, whenever ozone was aided by hydrogen peroxide or UV, the final COD was always below the Spanish threshold so that the effluent can be conducted to a municipal wastewater treatment plant, which according to the biodegradability results, will be able to handle with this stream. In fact, due to the high costs usually associated with ozone production it would be economically wiser to run ozonation only until reaching a stream able to be further treated in a biological reactor which generally comprises much lower operating costs.

Contrarily, Andreozzi et al. (2008) verified a slight COD removal when ozone was combined with Fe(III) and light. Nevertheless, it should be noticed that while in the previous studies UV lamps were used, in this case solar light was applied. Besides the raw effluent presented a higher COD load, which may explain this apparent discrepancies between the reported articles. It should still be pointed out that Andreozzi et al. (2008) analyzed the impact of single and solar/Fe(III) ozonation over OMW phytotoxicity since usually these wastewaters are used for soil irrigation; nevertheless, this parameter was only moderately reduced indicating that the use of partially treated OMW to irrigate agricultural lands should be carefully controlled.

\section{Integration with Other Technologies}

The application of integrated treatment methodologies may enhance global efficiency. Indeed Fenton's followed by ozonation showed interesting conclusions on the treatment of OMW (Garcia and Beltran-Heredia 2008; Martins et al. 2010) enabling high COD removals. In fact, according to previous industrial results of our research group (Martins et al. 2010), this procedure leads to a stream within the legal limits for its disposal throughout the local sewage guarantying suitable biodegradability which allows an efficient final depuration in the municipal wastewater treatment plant. This data was confirmed at the industrial scale in a plant built by our spin-off company Adventech (www.adventech.pt).

Biological systems are still the most widely spread wastewater treatment technology since are considered environmental friendly and operate at an acceptable cost. However, their efficacy is compromised when the effluent encompasses bio-refractory compounds. The integration between chemical and biological systems is usually reported has beneficial when compared with the individual processes (Mantzavinos and Psilakis 2004).

Due to the high chemical oxygen demand of olive mill wastewaters, their preferable treatment would be anaerobic digestion (Alonso et al. 2000). Moreover, this technology is recognized by its low cost, besides little energy and nutrients demand (Benitez et al. 1997). However, the presence of toxic compounds such as polyphenols and fat acids can compromise the stability of the reactor. In this ambit, ozonation can play an important role to remove such bio-refractory substances and, therefore, some studies are presented in literature involving the integration between these two technologies (Table 1).

Benitez et al. (1997) analyzed the direct application of anaerobic digestion to olive mill wastewater leading to methane yield coefficient $\left(\mathrm{Y}_{\mathrm{P} / \mathrm{S}}\right)$ of $194 \mathrm{~mL}$ of $\mathrm{CH}_{4} / \mathrm{g}$ of COD. The use of a prestage of ozonation reduced the phenolic content of the effluent (up to $94.3 \%$ of TPh removal) even if only a slight COD abatement occurred with this system (6.2\% of COD degraded). It should be referred that the process occurred at $\mathrm{pH} 4.84$ where direct ozonolysis is predominant which can explain the low COD depletion. The high phenolic load of OMW is the main source of toxicity over the methanogenic bacteria.

In fact, a high enhancement on the anaerobic decomposition of the effluent was attained when ozonation was applied as a pretreatment. This was demonstrated by the increase on $\mathrm{Y}_{\mathrm{P} / \mathrm{S}}$ which reached the value of $266 \mathrm{~mL}$ of $\mathrm{CH}_{4} / \mathrm{g}$ of COD in this case. These results pointed out that the chemical process can be used as a preliminary stage, which will remove most of the effluents' toxicity leading to a stream more amenable to be successfully bio-remediated in order to meet the discharge regulations.

Different results were though attained in the work by Andreozzi et al. (1998). Even if a high TPh removal was reached by ozonation (up to $75 \%$ in $7 \mathrm{~h}$ of reaction) accompanied by a decrease on lipids concentration (55\%) and negligible COD depletion, lower fermentation yields were detected when ozonation was applied as pre-treatment. Moreover, the increase of the pre-treatment time leads to a decrease on the methane yield and an augment in the anaerobic digestion lag phase. In fact, when the ozonation reaction time was higher than $3 \mathrm{~h}$ the biological process was completely inhibited. It was thus verified that ozonation, in this case, produced by-products toxic for methanogenic bacteria which were probably due to the decomposition of lipids and phenols. In fact, the authors concluded that the byproducts attained by the ozone degradation of oleic acid and p-hydroxybenzoic acid can be more inhibitory than the parent compounds.

It is important to stress that no negative impact was observed over acidogenic bacteria; thus ozonation intermediates are probably degradable under acidogenic conditions. In this context, the authors proposed the application of an acidogenisic step which could minimize the inhibitory effect over methanogenisis. These differences between the results attained by Benitez et al. (1997) and Andreozzi et al. (1998), somehow highlight the possible impact over the treatment efficiency of the effluent composition which is impossible to be totally known. In fact, OMW coming from different sources strongly varies with the kind of milling process, olives type and maturation (Mert et al. 2010; Paraskeva and Diamadopoulos 2006), which are not usually referred in the publications, making difficult generalizations about the most suitable depuration methodology. On the other hand, there are 
strong differences in the streams coming from different points of the mill such as fresh OMW or those coming from a stabilization pond where several wastewaters are joint together, which strongly changes the effluents chemical composition that will lead to different results when the same treatment is applied. This information should be clear in the reports so that a more general approach of the results present on scientific literature may be possible.

A different integrated scheme was proposed by (Beltran de Heredia and Garcia 2005) with anaerobic digestion preceding the ozonation stage. The biodigester operated under stable conditions during 2 months reaching up to $81 \%$ and $95 \%$ of $\mathrm{COD}$ and $\mathrm{BOD}_{5}$ removal, respectively. The remaining organic matter was attributed to biorefractory species such as polyphenols. Therefore, the application of a posterior ozone process to refine the effluent was discussed. In fact, a high $\mathrm{TPh}$ abatement was attained by ozonation (up to $89 \%$ after $4 \mathrm{~h}$ of reaction).

Even though the advantages of anaerobic digestion, some problems are associated with the operation of such sensitive reactors on the depuration of OMW, even after this wastewater suffering a previous chemical oxidation as verified by (Andreozzi et al. 1998). In fact, it is reported that the presence of poliphenolic compounds and fat acids promote instability on the digesters operation (Alonso et al. 2000). In this ambit, the aerobic biological treatments can be preferable due to their lower sensitivity to the referred inhibitory pollutants, even if some disadvantages can be ascribed to these processes. Among those drawbacks it can be pointed out the production of activated sludge, the need for introducing nutrients (such as nitrogen), besides the higher costs of operation, maintenance and installation (Alonso et al. 2000). Moreover, it is unlikely that by themselves, these biological depuration systems are able to totally remediate OMW since bacteria are not supposed to degrade bio-refractory species such as phenolic compounds. In this context, the integration between biological and chemical technologies seems the most advisable decision. Ozonation appears as a suitable option due to its high reactivity towards those complicated nonbiodegradable substances.

Benitez et al. (1999) studied the aerobic degradation of black olive wastewater with and without an ozonation pretreatment. The single aerobic degradation process was able to remove a high fraction of both COD (76-86\%) and TPh (50-80\%). In a second stage, the effluent was subjected to ozonation which promoted a slight COD removal that increased with the inlet ozone partial pressure (14-16\%); besides, a significant TPh depletion was possible by this chemical process (up to $76 \%$ ). It was thus expectable that this elimination of the inhibitory phenolic compounds could reduce the effluents toxic character before being further depurated in a biological step. When aerobic digestion was implemented after ozonation, $74-81 \%$ of COD and 50\% of $\mathrm{TPh}$ degradation was achieved which corresponded to global removal (ozonation + aerobic treatment) of $85 \%$ and $88 \%$ for $\mathrm{COD}$ and $\mathrm{TPh}$, respectively.
As it can be observed the efficiency attained by the processes integration is higher than the average values of each single system. Moreover, a kinetic study of the aerobic stage (single and after ozonation pre-treatment) was performed using the Contois model. It was concluded that the recourse to a preliminary chemical stage led to slightly higher values for the kinetic parameters $\left(\mathrm{K}=5.42 \times 10^{-2} \mathrm{~h}^{-1}\right.$, $\mathrm{Yx} / \mathrm{s}=0.280 \mathrm{gVSS} \mathrm{gCOD}^{-1}$ and $\mathrm{kd}=9.1 \times 10^{-3} \mathrm{~h}^{-1}$ ) than those detected when the biological process is applied to the raw effluent $\left(\mathrm{K}=4.81 \times 10^{-2} \mathrm{~h}^{-1}, \mathrm{Yx} / \mathrm{s}=0.279 \mathrm{gVSS}\right.$ $\mathrm{gCOD}^{-1}$ and $\left.\mathrm{kd}=1.92 \times 10^{-2} \mathrm{~h}^{-1}\right)$. Similar results were attained by (Beltran-Heredia et al. 2000a, 2000b) and (Benitez et al. 2002) using a similar effluent, which seems to point out a positive effect of ozonation as a preliminary step to improve aerobic degradation of the effluents by reducing their toxicity. It should be referred that the impact of temperature over ozonation was analyzed (Benitez et al. 1999; Beltran-Heredia et al. 2000a, 2000b; Benitez et al. 2002) being detected a mild positive effect which is due to the dual effect of this parameter over the process efficiency; if, in one hand, the degradation kinetic constants rose with temperature, the ozone solubility in water decreases. It is one of ozonation advantages the fact that the treatment may occur at room conditions not being required the reactors heating up, which would increase the operating costs.

The dilution of highly contaminated wastewaters with municipal effluents is reported as a promising technique, Rivas et al. (2000b) analyzed the effect of an ozonation prestage to improve biological aerobic depuration of a table olive processing effluent joint with urban wastewater. Ozonation is a quite interesting process for the treatment of such streams due to their alkaline character which will promote hydroxyl radicals formation.

Several experiments were performed about the impact of ozone inlet concentration over the process efficiency, being concluded that loads above $30 \mathrm{mgO}_{3} / \mathrm{L}$ had no further significance over COD removal. For those conditions more than $70 \%$ of COD was degraded in 150 min. However, $\mathrm{BOD}_{5}$ also decreased along the reaction which can compromise the resulting effluent biodegradability. In other hand it the possible impact of the presence of radical scavengers in the effluent that may reduce the efficiency of hydroxyl radicals in the treatment was not analyzed. This is an important issue since these moieties may be naturally present in the effluents composition.

Ozonation prior to an aerobic stage has to fulfill two goals: lower the effluent $\mathrm{pH}$ until neutrality and remove the nonbiodegradable compounds, enhancing this way the effluents' biodegradability. It was concluded that if the ozonation time was shortened to 35 min (Rivas et al. 2000b), the $\mathrm{pH}$ of the wastewater decreased from 11.5 to $7.5-8$, which is within the optimal range to implement a biological treatment. Besides, a strong $\mathrm{TPh}$ reduction occurred leading to the formation of smaller and more oxygenated compounds more amenable to be bio-processed. In fact, for this reaction time the biodegradability of the effluent rose since the 
$\mathrm{BOD}_{\mathrm{f}} / \mathrm{COD}_{0}$ increased from 0.76 (raw effluent) to 1.15 (ozonated stream). The further treatment of the pre-ozonated wastewater with acclimated activated sludge led to a COD removal of about $80 \%$, highlighting the efficiency of the ozonation and aerobic systems integration for the depuration of such cumbersome streams.

The reverse scheme involving aerobic biological oxidation followed by ozonation was analyzed for black olive wastewaters (Beltran-Heredia et al. 2000a). Activated sludge showed interesting COD removal results (76\%-90\%); however, slighter efficiency was attained regarding the abatement of the stream phenolic content (46-74\%). Conversely, the ozonation of the raw effluent led to moderate COD removal values (42-55\%) and satisfactory TPh degradation (67-75\%). The application of ozonation to the effluent previously biologically depurated yielded to a global COD conversion of $62 \%$ (higher than when ozone was used to the raw stream). This enhancement was attributed to the preliminary removal of most of the biodegradable organic matter by the microorganisms, while ozonation degraded the remaining bio-refractory compounds (such as polyphenols).

An increase on ozonation kinetic parameters was thus observed when this treatment was preceded by the aerobic system. Similar results were attained by (Benitez et al. 2001) reaching between 90-93\% of COD removal when ozonation was applied to aerobically pretreated wastewater. It should be noticed that generally table olive processing wastewater presents lower COD and TPh loads than those found in OMW, which may somehow explain the efficiency observed when activated sludge is directly applied. In other hand, the stability of the bio-reactor, whenever a sharp change on the effluents composition/flowrate occurs, was not addressed.

This is the main drawback on the direct application of biological treatment systems. In our opinion it seems more advisable to use ozonation in a prior step so that some equalization and toxicity removal may take place before feeding the effluent to activated sludge; this way the chemical process may help to keep the bio-reactor stabilized by controlling the characteristics of the inlet wastewater. The integration between aerobic treatment and ozonation was also studied for the treatment of olive oil extraction wastewater (Lafi et al. 2009) which, generally, are characterized by higher organic loads $\left(\mathrm{COD}=117.1 \mathrm{~g} \mathrm{~L}^{-1}\right)$. The effluent was previously centrifuged and diluted leading to a COD of about $12 \mathrm{~g} \mathrm{~L}^{-1}$. The application of single ozonation during $3 \mathrm{~h}$ led to less than $22 \%$ of COD abatement whereas aerobic biodegradation was able to remove up to $70 \%$ of COD.

The integration between these two processes was analyzed using the two possible schemes (aerobic biodegradation followed by ozonation and ozonation followed by aerobic biodegradation). Both overall sequences promoted more efficient treatment than the individual technologies. However, the COD removed using aerobic biological treatment of the wastewater previously treated by ozonation was slightly higher ( $87 \%$ compared with the $80 \%$ achieved by the sequence aerobic biodegradation followed by ozonation). This was attributed to the ozonation capability to convert initial toxic and bio-refractory compounds into by-products more amenable for bio-processing.

Gathering up all these results it seems a good option to integrate ozonation as a pre-treatment before a less expensive activated sludge reactor. However, it is still lacking analyses involving the possible impact of the seasonal composition and production load inherent to these agro-effluents over the behavior of the microorganisms. Besides, since the wastewater is only produced during a short period of the year, it would be probably more feasible to chemically pre-treat the effluent in situ until the fulfilling of the legal thresholds, reaching a non-toxic and biodegradable stream. Afterwards, it would be conducted to the local sewage to be ultimately depurated in the municipal wastewater treatment plant, rather than try to run a totally devoted activated sludge reactor, which would require stronger maintenance and control. In fact, even if a high load of effluent is produced during a few months (generally from October to February), in the rest of the year it would be difficult to maintain the activated sludge (due to the lack in feeding wastewater). The microorganisms would have then to be acclimated once again in the next campaign which is time and money consuming.

\section{Catalytic Ozonation}

Ozone action can be enhanced by the application of suitable catalysts, either homogeneous or heterogeneous (Nawrocki and Kasprzyk-Hordern 2010). The use of solid materials allows the retrieval of the catalyst at the end of the process facilitating their reuse. Even if several studies are found regarding the application of catalytic ozonation for the degradation of model compounds, literature is scarce in what concerns real effluents. Carbajo et al. (2007) tested a perovskite type catalyst for the ozonation of several phenolic wastewaters and among them OMW. This effluent is hardly oxidized by single ozonation (roughly $40 \%$ of COD was abated in $320 \mathrm{~min}$ ), but, meanwhile, the addition of $1 \mathrm{~g} \mathrm{~L}^{-1}$ of perosvkite enhanced COD removal to up to $70-75 \%$. It was not necessary to introduce the catalyst at the beginning of the process, since some of the initial pollutants have some ability to be directly oxidized by ozone such as phenolic compounds; perosvkite will be thus required to enhance the oxidation of intermediate refractory organic compounds that remain in solution.

From the analysis of the role of the catalyst over the depuration pathway, it was concluded that the addition of radical scavengers had no effect on the process efficiency meaning that the organic compounds degradation occurs mainly throughout surface reactions than by the generation of radicals which would oxidize the pollutants in the liquid bulk. In fact, it can be interesting to enhance molecular ozone reactions rather than hydroxyl radicals' pathways, since real wastewater may encompass in their composition compounds able to scavenge hydroxyl radicals compromising, this way, the treatment efficiency (Kasprzyk-Hordern et al. 2003). 
Martins and Quinta-Ferreira (2011b) compared single ozonation with the cases where ozone was enhanced by the laboratory $\mathrm{Mn}-\mathrm{Ce}-\mathrm{O}$ and the commercial Fe-Mn-O catalysts, in the depuration of OMW. Catalytic ozonation improved COD removal from $10 \%$ to $27 \%$ for Fe-Mn-O and to $42 \%$ for $\mathrm{Mn}-\mathrm{Ce}-\mathrm{O}$. Moreover, the effluents $\mathrm{BOD}_{5} / \mathrm{COD}$ reached 0.43 (Fe-Mn-O) and 0.51 (Mn-Ce-O), above the threshold of 0.4 generally indicated for highly biodegradable streams (Esplugas et al. 2004), strengthening that the treated wastewater can be conducted to an aerobic biological system to be further refined.

These studies highlight the relevance of pursuing investigation regarding catalytic ozonation for the abatement of real olive processing wastewater. Besides screening further catalytic formulations, data about catalyst lifetime and regeneration options should be tested and reported. In fact, especially when dealing with transition metals, active species leaching may be an important drawback for industrial application, summing up the possibility of catalyst poisoning by carbonaceous deposits that will block the access to active sites. In this line, it is absolutely required to perform catalytic tests in continuous mode so that catalytic behavior during several days/weeks of operation may be reported to give industry reliable data about the real applicability of this process

\section{Winery Wastewater}

Wineries and other grape related industries generate large volumes of wastewaters which can be classified as cellar wastes (from the production of wine) and distillation effluents (for the production of liquors and other distillate beverages) (Strong and Burgess 2008).

Wine production is an important industry in Mediterranean Sea area countries; for example, in Portugal in 2010 about $7,132,706 \mathrm{hL}$ of wine were produced according to the Statistics Portugal Institute (INE). Cellars produce annually large amounts of liquid effluents coming from the many processing and cleaning operations (Agustina et al. 2008). Their composition is dependent on the wine styles and kind of processing and cleaning operations used in each specific winery.

This means that the effluents characteristics are very variable; moreover, winery wastewater suffers from high seasonal fluctuations in volume and composition which are related with the working period (vintage, racking and bottling) (Braz et al. 2010). In this context, even if a high BOD is attributed to these streams, the application of biological treatment systems can be compromized by the constant flow and pollutant load changes; in fact if during the vintage high flow and charged effluents are produced, during the rest of the year bacteria are hardly maintained due to the low organic load of the wastewater. In other hand, the presence of bio-refractory and toxic compounds (such as polyphenols) can limit the applicability and efficiency of such depuration methodologies (Lucas et al. 2009).

In this sense, the application of chemical oxidation as a pretreatment besides improving biodegradability and removing toxicity may somehow equalize the composition of the effluent entering the activated sludge reactor safeguarding its stability. Ozonation can thus play an important role on the treatment of these effluents due to its activity on removing phenolic and other unsaturated compounds.

\section{Single Ozonation}

Gimeno et al. (2007) tested single ozonation for the treatment of winery wastewater at $\mathrm{pH} 7$ (Table 2) achieving up to $37 \%$ of COD removal in 120 min of reaction; however, mineralization was very low (TOC depletion of around $15 \%$ ). This means that ozone is able to partially oxidize organic matter leading to the accumulation of oxygenated species but total oxidation to carbon dioxide and water is not the preferred route. A slight improvement was observed for COD removal when ozonation was carried out at $\mathrm{pH}=11$ due to the catalytic ozone decomposition by hydroxide anions leading to $\mathrm{HO}^{\bullet}$.

Nevertheless, TOC values were not much different than the ones attained for acidic conditions. Due to the breakage of complex molecules (such as phenolic compounds) into more oxygenated compounds, one could admit that the effluents biodegradability would be enhanced by ozonation; even so, from the BOD analysis it was verified that the treated stream contained more bio-recalcitrant compounds than the original one. It should be noticed though that non-acclimated microorganisms were used in the BOD determination which means that probably higher degradation would be expected in a bio-reactor properly acclimated to the pre-ozonated effluent.

Ozone ability to degrade phenolic compounds present in winery wastewaters was clear in our previous results (Martins et al. 2009) since total $\mathrm{TPh}$ removal was attained by single ozonation $(\mathrm{pH}=3)$ in $60 \mathrm{~min}$. In addition, a high efficiency was observed for color depletion $(66 \%)$ once this parameter is generally related with the presence of substances encompassing high electronic density groups which are reactive with ozone. Ozonation showed to be an interesting alternative for suspended solids removal with up to $85 \%$ of TSS degraded in 60 min of ozonation. Besides promoting solids surface oxidation, ozone also presents charge neutralization characteristics (Rueter and Johnson 1995), this is an important issue since solid wastes disposal is an strong environmental problem nowadays.

However, even if a significant COD abatement of 54\% was observed, less than $2 \%$ of mineralization was attained, meaning that the organic compounds partial oxidation is the preferred reaction route. Since alkaline conditions can improve ozonation TOC removal, tests were carried out at $\mathrm{pH}=10$; nevertheless, no significant improvement was observed probably due to the presence of radical scavengers in the stream (such as carbonates) which reduce hydroxyl radicals performance.

Lucas et al. (2009), analyzed the behavior of a pilot-scale bubble column for the depuration of winery wastewater by ozonation. The effect of $\mathrm{pH}$ was analyzed within the range 


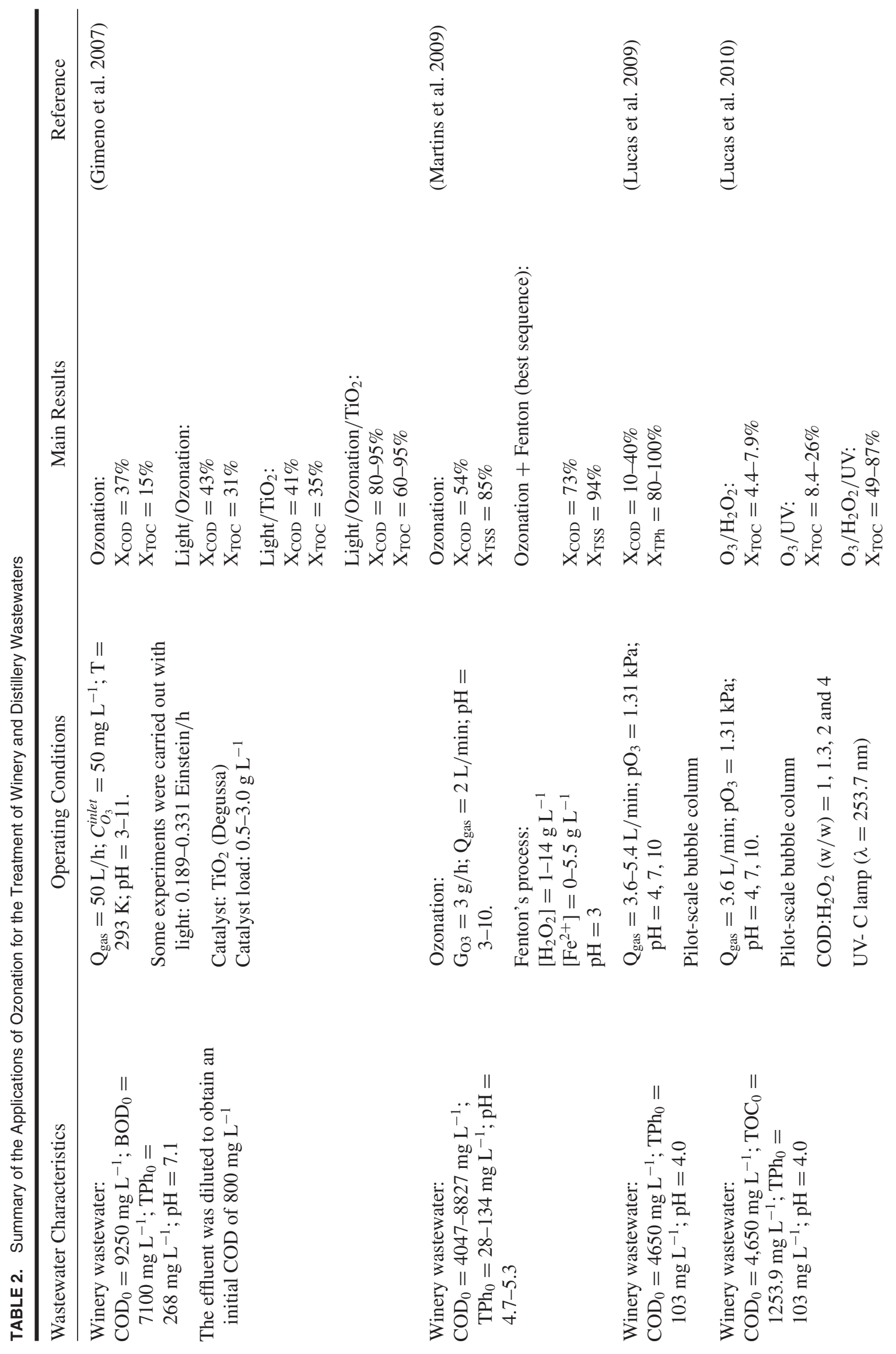




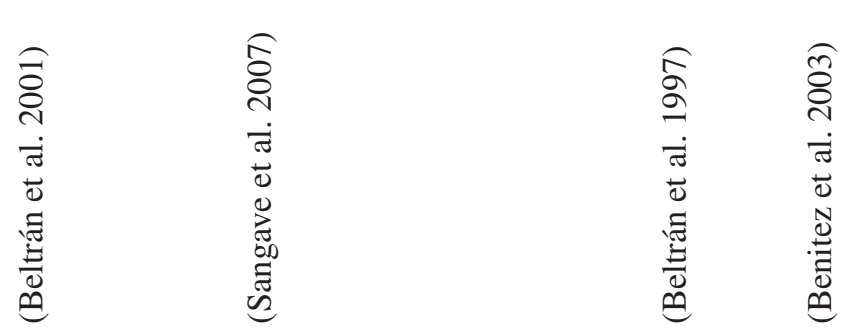

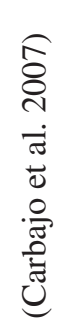
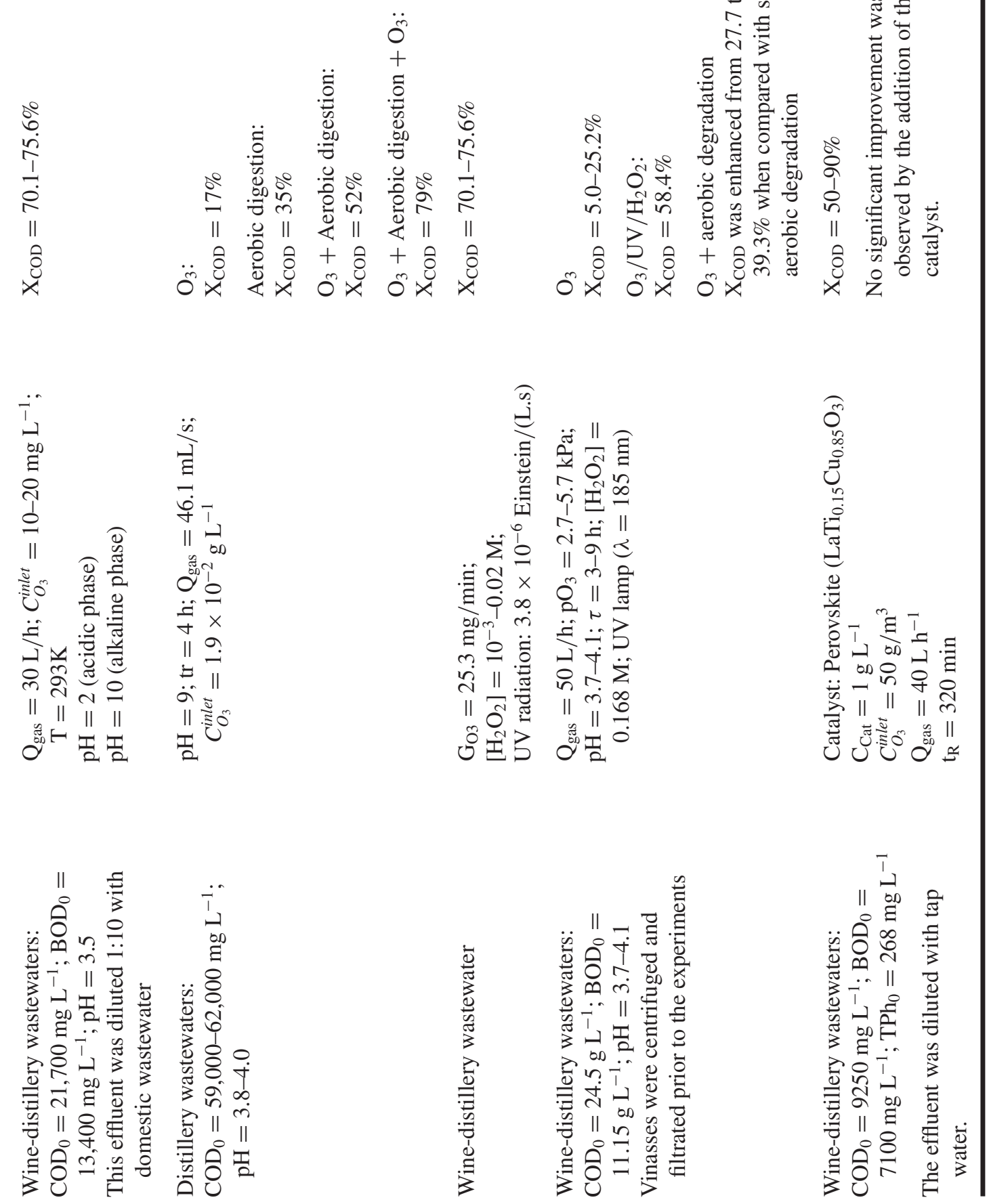


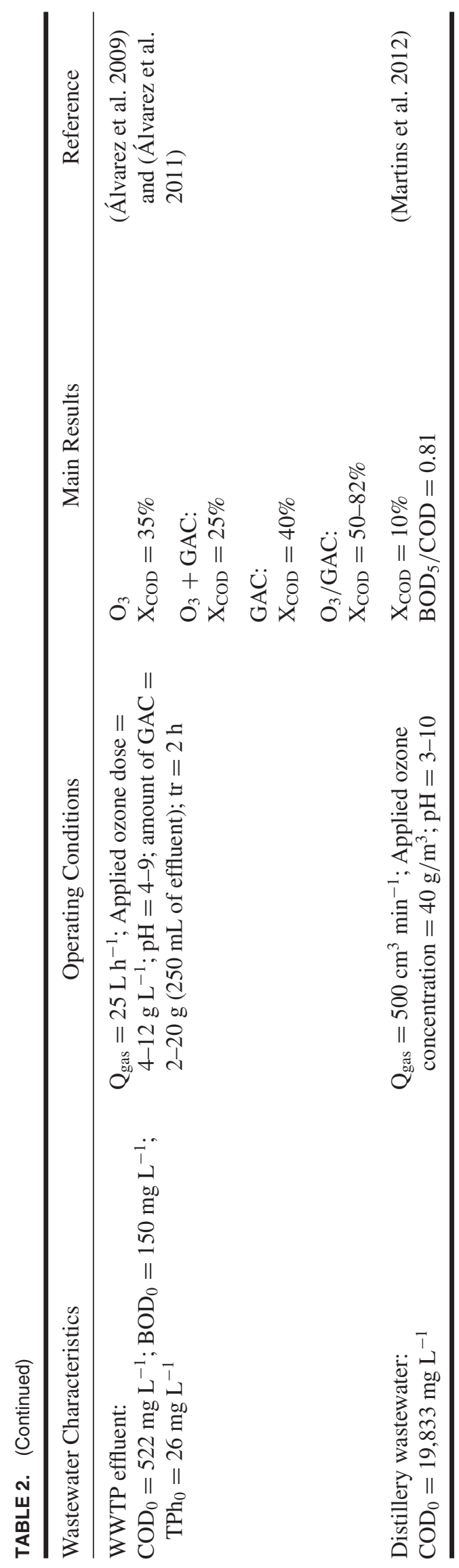


4-10 and these values were not controlled throughout the reaction. It was observed that, whichever the initial value, $\mathrm{pH}$ decreased along time and more sharply for higher initial pHs. This was attributed to the formation of low molecular weight carboxylic acids during the oxidation and some carbonic acid due to the mineralization. COD removal increased from $10 \%$ to $40 \%$ in $180 \mathrm{~min}$ when $\mathrm{pH}$ rose from 4 to 10 . However, the reverse was identified in what regards $\mathrm{TPh}$ abatement, with lower values achieved for alkaline conditions.

This suggests that molecular ozone (main oxidant at acidic $\mathrm{pH}$ ) is more selective towards those compounds than hydroxyl radicals (main oxidants at alkaline conditions) which will react with other organics in solution. From the analyses of $\mathrm{pH}$, oxidation reduction potential and ozone consumption, the kinetic regimes (fast, moderate and slow) were identified during the reaction, and it was concluded that the regime changed along time due to variations on water composition and oxidant species. In this ambit, besides being recommendable to carry out this type of reaction (gas-liquid) in bubble columns (large bulk volume), the selection of the gas-liquid contactor should consider high contact surface area to volume ratios if the reaction occurs mainly in the gas-liquid interface (fast or moderate kinetic regime).

\section{Ozonation Aided by Light $/ \mathrm{H}_{2} \mathrm{O}_{2}$ and Catalysts}

To aid $\mathrm{O}_{3}$ action, Gimeno et al. (2007) observed that the combination between ozone and light slightly improved COD degradation (43\%) when compared with the $37 \%$ attained by single ozonation. A high enhancement on mineralization was detected (up to $31 \%$ of TOC removed) against $15 \%$ reached by $\mathrm{O}_{3}$, pointing out that the presence of light mainly pushes the degradation pathway towards total mineralization rather than partial oxidation.

Lucas et al. (2010) tested several ozone-based AOPs $\left(\mathrm{O}_{3} / \mathrm{UV}\right.$ and $\left.\mathrm{O}_{3} / \mathrm{H}_{2} \mathrm{O}_{2} / \mathrm{UV}\right)$ at a pilot-scale for the depuration of winery wastewater. Photolytic ozonation was able to remove COD between $8.4(\mathrm{pH}=4$ and 7$)$ and $26 \%$ $(\mathrm{pH}=10)$ in $300 \mathrm{~min}$. This higher degradation rate at alkaline conditions was related with the highest availability of hydroxyl radicals which are also formed by ozone self-decomposition promoted by the hydroxide ions. $\mathrm{O}_{3} / \mathrm{H}_{2} \mathrm{O}_{2} / \mathrm{UV}$ combined process was much more efficiency on the abatement of the pollutant character of the effluent leading to $40 \%(\mathrm{pH}=4), 40 \%(\mathrm{pH}=7)$ and $57 \%(\mathrm{pH}=10)$ of COD removal once more pointing out the highest efficiency of alkaline conditions. In this system, additional hydroxyl radicals are produced due to the presence of hydrogen peroxide. However, above a certain concentration, there is an excess on this reactant which can scavenge hydroxyl radicals reducing, thus, the process efficiency.

In this context, it was identified that the best removal rate is attained when a ratio COD: $\mathrm{H}_{2} \mathrm{O}_{2}=2$ is used. Comparing ozone consumption (difference between the values of ozone flow at the reactors inlet and outlet) by single ozonation (Lucas et al. 2009) with $\mathrm{O}_{3} / \mathrm{UV}$ and $\mathrm{O}_{3} / \mathrm{H}_{2} \mathrm{O}_{2} / \mathrm{UV}$, a much higher ozone consumption rate was observed in the former processes meaning that a more efficient use of the introduced ozone is attained with this combined systems reducing this way ozone demand and waste.

Photocatalytic ozonation (using $\mathrm{TiO}_{2}$ as photocatalyst) was very efficient both for COD and TOC removals within the ranges of 80-95\% and 60-95\%, respectively (Gimeno et al. 2007). Catalyst concentration showed to be a crucial parameter, since the increase on its load promoted TOC initial decrease rate; however, above a certain value, the particles tend to shield emitted radiation decreasing thus the degradation kinetic rate. $\mathrm{pH}$ effect was also evaluated for this system and, contrarily to single ozonation, the best degradation was achieved for acidic conditions probably due to the better pollutants adsorption on the catalyst surface which was considered as a key step on this process. Moreover, at alkaline $\mathrm{pH}$ values, ozone is decomposed into hydroxyl radicals reducing, then, the availability of molecular ozone to play its part in electron trapping and electro-hole recombination.

\section{Integration Strategies}

To improve winery wastewater depuration, several integrated strategies were tested by Martins et al. (2009) involving flocculation, Fenton's oxidation and ozonation. It was concluded that a flocculation stage would not be necessary since ozonation was able to satisfactorily remove TSS. This is industrially interesting because it will not be required sedimentation tanks and sludge management systems. Moreover, environmentally speaking, solids destruction is also preferable avoiding the need of sludge disposal. Among the tested treatment sequences it was concluded that the most efficient would involve ozonation followed by Fenton's process leading to a final TSS and COD removal of 94 and 73\%. This enhancement was attributed to the formation of low molecular weight carboxylic acids (such as oxalic acid) during ozonation which can improve iron catalytic activity towards the formation of hydroxyl radicals in Fenton's oxidation due to their action as organic ligands (Parsons 2004).

\section{Distilleries Wastewaters}

Distilleries produce high polluted wastewaters with large organic loads (Beltran de Heredia et al. 2005). The presence of phenolic compounds and the high variations on the streams composition generally makes biological depuration an unsuitable option. Unsaturated organic substances prone to electrophilic attack seem to indicate that ozonation can be an advisable technology for such effluents (Beltrán et al. 2001).

\section{Single and Integrated Ozonation}

Single ozonation was applied on the treatment of mixed domestic and wine-distillery wastewaters (10:1 v/v) using several pH-sequential schemes treatments (Beltrán et al. 2001). The use of acidic and alkaline cycles, especially when 
two acidic $(\mathrm{pH}=4)$-alkaline $(\mathrm{pH}=10)$ steps of 10 and $50 \mathrm{~min}$, respectively, were applied during the chemical treatment, was able to maintain high oxidation rates during all the process, while, when $\mathrm{pH}$ was fixed to a value (either alkaline or acid), after an initial period of high-degradation, a stationary COD value is attained. During the acidic periods, phenolic and other unsaturated compounds are removed; moreover, inorganic carbon can be stripped favoring the application of a subsequent radicalar pathway.

In fact, carbonates and bicarbonates naturally present in the wastewater can act as radical scavengers reducing, this way, the action of the $\mathrm{HO}^{\bullet}$ generated by ozone self-decomposition for high $\mathrm{pH}$ values. Besides the high COD removal attained by this procedure, an improvement on the effluents BOD/COD ratio was detected which means that the by-products are more amenable for bio-processing. In fact, the use of an ozonation pre-treatment increased aerobic oxidation of a distillery wastewater (Sangave et al. 2007) reducing in 3 times the time required by the activated sludge reactor. It means that lower volume reactors would be needed with this combined system. Finally, the application of a polishing stage with ozone (after ozonation + aerobic biological system) during 30 min truly improved decolorization and a COD removal of about $79 \%$ was attained after the combined technology.

In a previous work of our research group (Martins et al. 2013), where integrated schemes involving Fenton's process and ozonation were compared for the depuration of a high strength distillery wastewater $\left(\mathrm{COD}_{0}=19833 \pm\right.$ $160 \mathrm{mgO}_{2} / \mathrm{L}$ ) it was concluded that even if ozonation was unable to satisfactorily remove COD (below 10\%) when compared with Fenton's peroxidation; the application of an ozone stage (either before or after Fenton's) was very important to improve biodegradability $\left(\mathrm{BOD}_{5} / \mathrm{COD}=0.81\right)$.

Beltrán et al. (1997) analyzed the oxidation of distilleries wastewaters by ozone combined with hydrogen peroxide or UV. No improvement was observed when ozone was aided by hydrogen peroxide, since COD removal was slightly the same in both cases. However, a high enhancement compared with single ozonation was detected by $\mathrm{O}_{3} / \mathrm{UV}$ leading to 21.5 and $19.5 \%$ of COD and TOC removal, respectively after $2 \mathrm{~h}$ of oxidation at $\mathrm{pH}=4$. No difference was observed between single ozonation and $\mathrm{O}_{3} / \mathrm{UV}$ for $\mathrm{pH} \geq 9$. Besides, the amount of ozone leaving the reactor was much lower when ozonation was combined with UV which means that ozone is more efficiently used in this case when compared with the single process.

The application of ozonation and ozonation aided by UV and hydrogen peroxide was tested in the degradation of wine vinasses (Benitez et al. 2003). An improvement was observed comparing single ozonation with the case where ozone was aided by both hydrogen peroxide and UV radiation. Indeed, the maximum COD depletion attained by single ozonation was $25.5 \%$ (for the highest hydraulic retention time in the reactor, $9 \mathrm{~h}$ ), whereas up to $58.4 \%$ was achieved by the combined system. Also more efficient ozone usage was verified for the $\mathrm{O}_{3} / \mathrm{H}_{2} \mathrm{O}_{2} / \mathrm{UV}$ system. In fact, while for single ozonation a consumed ozone yield of $50 \%$ was detected, $78 \%$ was attained for $\mathrm{O}_{3} / \mathrm{H}_{2} \mathrm{O}_{2} / \mathrm{UV}$. Due to the high ability of ozone to remove bio-recalcitrant and toxic substances (high total aromatic compounds depletion was observed even for single ozonation), its suitability to be used as pre-treatment before an activated sludge reactor was analyzed.

Thus, the degradation achieved by aerobic digestion was compared when the raw and pre-ozonated effluent was fed to the bio-reactor. Some enhancement was observed by using the previous chemical oxidation since a global COD removal (ozonation + aerobic digestion) of $39.3 \%$ was reached when compared with roughly $27.7 \%$ when the activated sludge is applied directly to the initial wastewater. This strengthens that ozonation can be an interesting pre-treatment before biological systems by degrading toxic compounds leading to by-products more amenable for bio-degradation.

\section{Catalytic Ozonation}

As referred before, the addition of a suitable solid catalyst has proven to truly enhance ozonation of some recalcitrant wastewaters (Nawrocki and Kasprzyk-Hordern 2010). In what regards distillery wastewaters, Carbajo et al. (2007) tested the ability of perovskite for the catalytic ozonation of such streams. Ozone at $\mathrm{pH}=7$ was found to be quite efficient for the degradation of the effluent (diluted 1:10 with tap water) with up to $90 \%$ of the COD depleted in $360 \mathrm{~min}$. In fact, a decrease on COD degradation to $70 \%$ was detected when perovskite was added to the reactor at the beginning of the experiment which was attributed to the ozone decomposition at the catalyst surface impeding its direct attack to easily reactive molecules (such as phenolic compounds).

Thus, the possibility of introducing the catalyst only after some treatment time $(2 \mathrm{~h})$ was tested along which by-products refractory to ozone direct attack were produced; however, no significant improvement was observed between the single and catalytic run. Similar results were attained when single and catalytic ozonation were carried out at $\mathrm{pH}=3$. It seems thus that, in this case, no improvement is attained by using a solid catalyst; however, only one material was tested. Besides, the conclusions were drawn by taking into account the impact over COD alone and no reference is made for other parameters such as biodegradability or toxic character of the treated effluent which may be very different from those obtained by single ozonation, since the presence of the catalyst may push the reaction pathway for a different route leading to more bio-amendable by-products.

Indeed, the selection of a catalyst should bear in mind not only the abatement of organic load but also its impact over parameters such as biodegradability and toxicity, along with its stability throughout time. Álvarez et al. $(2009,2011)$ analyzed ozone catalyzed by granular activated carbon (GAC) for the treatment of an effluent from a full-scale wastewater treatment plant that treats streams coming from several foodprocessing industries nearby, such as wineries, distilleries and olive mills. The wastewater was collected at the exit of the 
activated sludge settler and still presented a COD value of $522 \mathrm{mg} \mathrm{L}^{-1}$, which is above the legal limit for the direct disposal throughout the natural water courses.

Single ozonation, single adsorption and application of GAC after the ozonation reactor, to remove the oxidation byproducts, were analyzed. At the end of each process COD removals of $35 \%, 40 \%$ and $25 \%$ were attained, respectively. It seems thus that the partially oxidized organic intermediates coming from ozonation are not suitable to be adsorbed onto GAC surface. Therefore, simultaneous $\mathrm{O}_{3} / \mathrm{GAC}$ was tested and the impact of several operating conditions was assessed. The presence of GAC improved the ozonation with COD abatements within the range $50 \%-82 \%$ in $2 \mathrm{~h}$ of reaction. Contrarily to what was expected, $\mathrm{pH}$ showed negligible effect over the $\mathrm{O}_{3} / \mathrm{GAC}$ process.

This was attributed to the contradictory effect of this parameter over the several processes involved in COD depletion. Although alkaline solutions promote ozone decomposition into the high reactive hydroxyl radicals, these conditions showed to inhibit pollutants adsorption on GAC surface. Moreover, the influence of $\mathrm{pH}$ over ozone decomposition on GAC surface is still not clear. Continuous experiments were conducted to verify the suitability of the industrial application of this technology. Although single ozonation reached a steady-state COD abatement of $20 \%$, the catalytic ozonation over GAC led to $35 \%$ of COD removal and low deactivation was detected over time, which was related with the in situ regeneration of GAC due to ozone oxidation.

The high organic charge and probable presence of radical scavenger substances in these high strengthen effluents somehow difficult ozone action; nevertheless, ozonation integration with traditional activated sludge reactors arises once more as an interesting option.

\section{Pulp and Paper Industry Wastewater}

Pulp and paper is an important industry worldwide (Ko et al. 2009). Pulp and paper production uses high water loads generating, this way, significant effluent streams usually characterized by soaring $\mathrm{COD}$ and $\mathrm{BOD}_{5}$ values. Pollutants are generated during the various process stages and the wastewater composition is variable with the type of wood materials, process applied and management practices regarding effluents recirculation for recovery (Pokhrel and Viraraghavan 2004).

Wastewater is generated along all the pulp and paper production steps with highly different characteristics (Pokhrel and Viraraghavan 2004): wood preparation (high load in suspended solids and BOD); digester house (resins, fatty acids, color, BOD, COD, AOX and VOCs); pulp washing (high $\mathrm{pH}$, BOD, COD and suspended solids); pulp bleaching (lignin, color, COD, AOX, inorganic chlorine, organic chlorine and VOCs) and paper making (particulate waste, organic compounds, inorganic dyes and COD). Thus, the effluents are very complex variable and constitute an important environmental danger. Several authors report toxic effects over ecosystems when in contact with this type of streams (Ericson and Larsson 2000; Owens et al. 1994; Pokhrel and Viraraghavan 2004).

Pokhrel and Viraraghavan (2004) indicate, based on a literature review, that both aerobic and anaerobic treatments can be applied for the degradation of pulp and paper mill effluents; however, it is pointed out that chemical processes should be used to promote chlorinated phenolic compounds, AOX (adsorbable organic halides) and color depletion since these substances tend to be refractory to microorganisms. Ozonation can thus play an important role in this field probably integrated with biological approaches to minimize costs.

\section{Single Ozonation}

Zhou and Smith (1997) analyzed the treatment of pulp mill wastewater by ozonation and concluded that the process was only dependent upon the amount of ozone utilized regarding color and AOX removal. In a subsequent work (Zhou and Smith 2000), the same authors performed bench and pilotscale tests involving the ozonation of pulp mill wastewaters over a large range of operating conditions; besides, the reproducibility of the results attained at a larger scale was addressed (Table 3).

Wastewater samples were taken from several points of the existing two-stage aerated lagoon actually used for the effluent treatment (before, between the two lagoons and after the settling basin after the biological treatment). The main goal was to determine the best location to install an ozonation system to refine the polluted stream before being discharged to a nearby river. The results revealed that ozone was very efficient removing color and AOX with high initial rates leading up to $80 \%$ and $50 \%$ of degradation, respectively. However, low COD abatement was attained (22\%), probably due to saturated refractory by-products formation. This chemical process was more efficient for the depuration of biologically treated streams than for the raw effluent, which was related with the removal of biodegradable compounds more refractory to ozone which could also compete by $\mathrm{O}_{3}$.

Regarding these results, it seems that ozonation should be used as a polishing step after the biological system. To analyze ozone absorption, $\mathrm{O}_{3}$ off-gas was determined and it was verified that it increased along the reaction time. This was related with the high complexity of the wastewater; in a first step, the compounds readily reactive with ozone are quickly degraded enhancing thus ozone absorption. This enhancement declines during time due to the accumulation of substances more refractory to ozonation reducing thus the amount of reactant adsorbed and augmenting ozone off-gas, which was also related with the ratio of superficial gas to liquid velocity, mean hydraulic retention time, inlet ozone concentration, flow characteristics and backmixing. Models to predict the amount of ozone leaving the reactor were developed and it was concluded that it was possible to run an ozonation system without an off-gas ozone control system (off-gas ozone has to be lower than $1 \mathrm{ppm}$ as legally imposed) by controlling ozone absorption. 


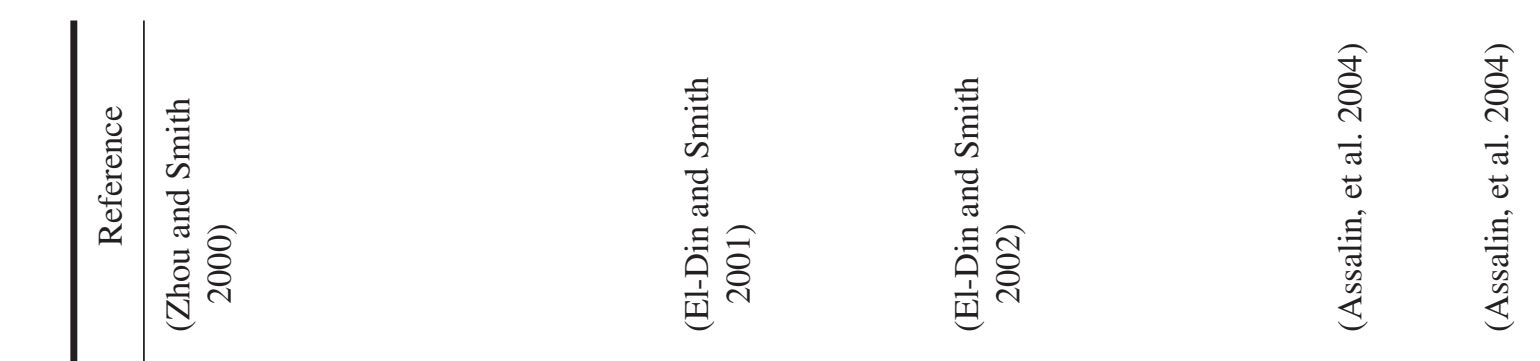

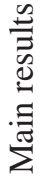

ते

\|I $\|$

它苍苍

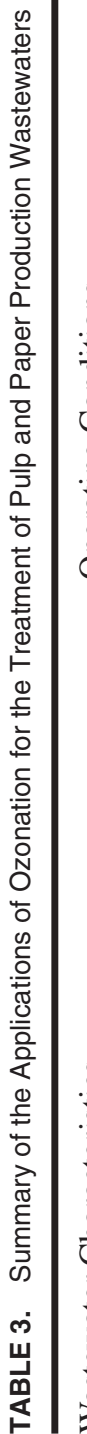

0
0
0
0
0
0
$\vdots$
0
0

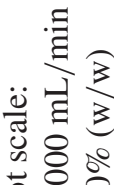

ํㅡㅇ ำ

छ을

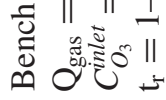

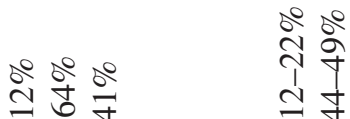

|| || ||$\quad$ || ||

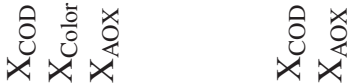

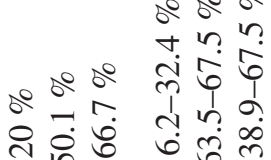

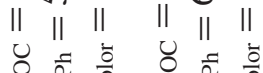

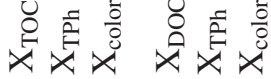
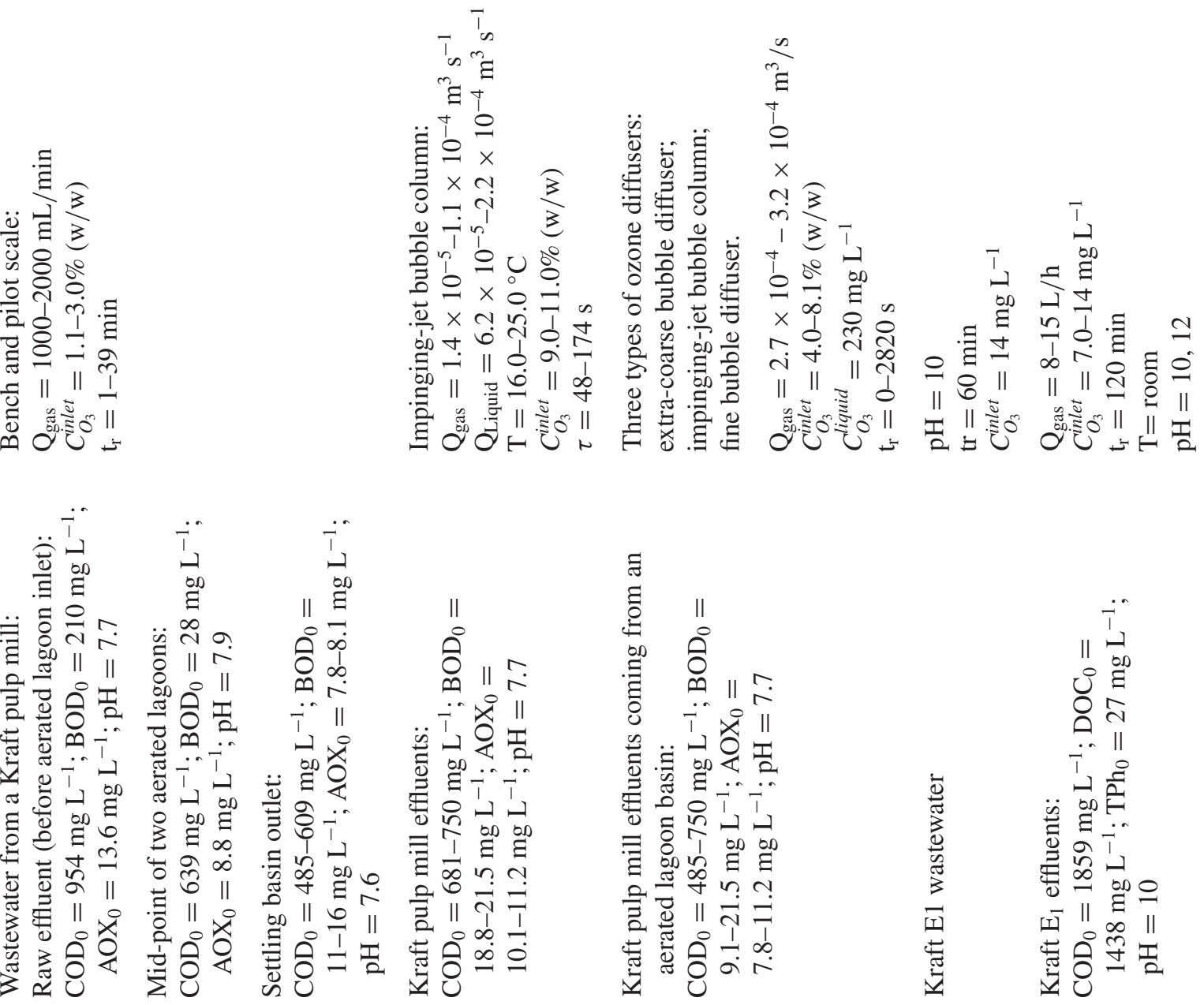

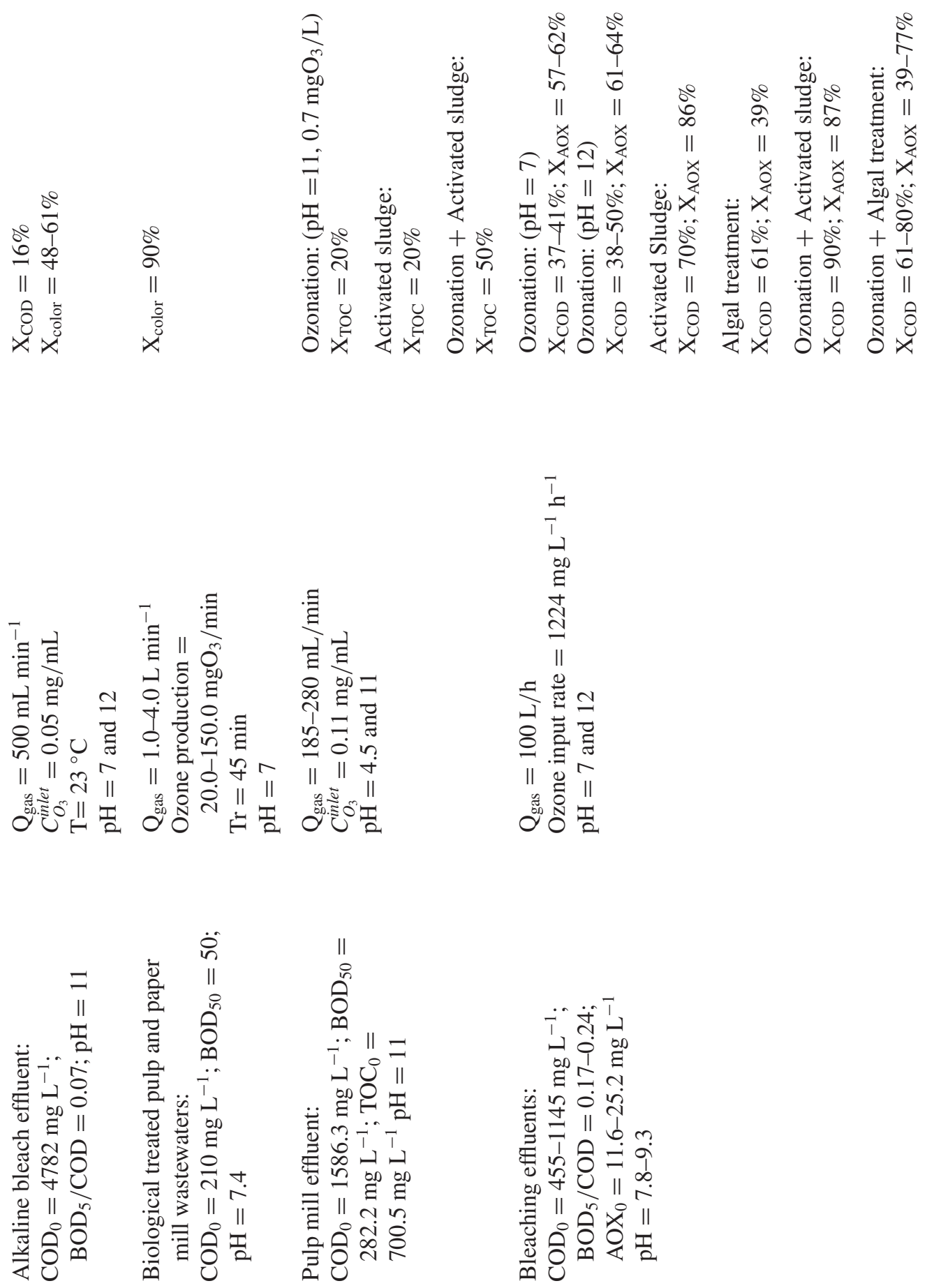


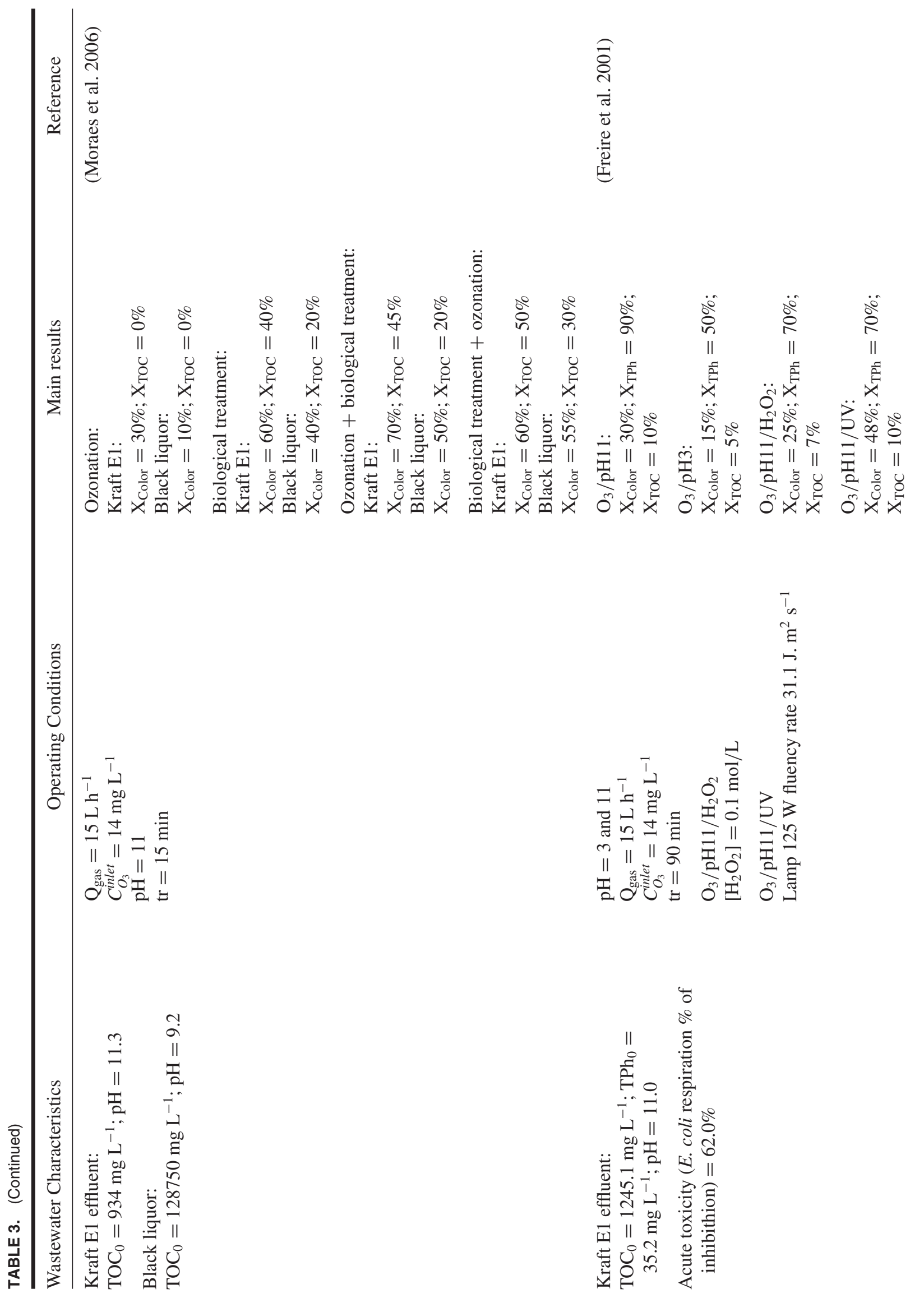




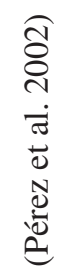

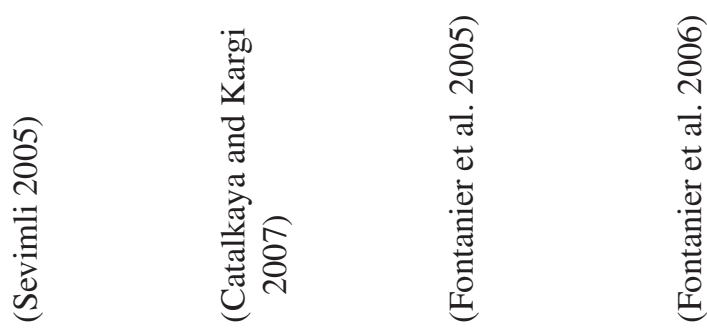

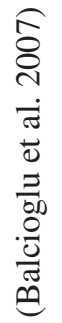
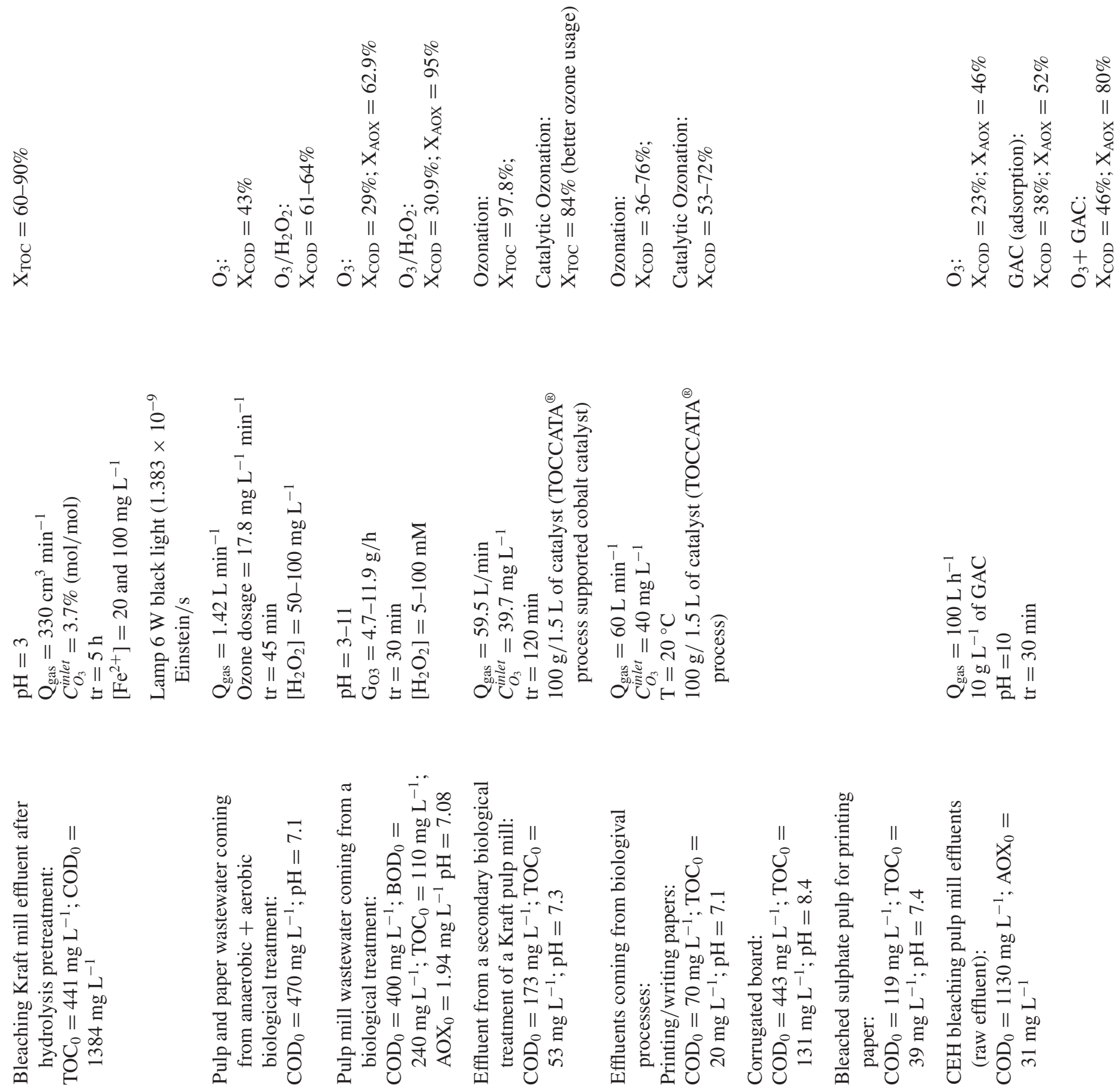
Thus, the ozone contactor should be high enough to guarantee gas-liquid contact since most of ozone absorption occurs in the bottom of the column; moreover, operating in countercurrent and increasing mean hydraulic retention time showed to lead to lower off-gas ozone. Similar results were attained by (El-Din and Smith 2001) when analyzed Kraft pulp mill effluents ozonation in an impinging-jet bubble column. Higher enhanced mass transfer coefficients were determined for the initial reaction times and considerably lowering along the treatment was further detected.

Besides the high ozone potential on removing color and AOX, it was verified a significant increase on the effluents biodegradability after ozonation, due to the decomposition of bio-refractory long-chain-high-molecular-weight compounds. This means that the integration between ozonation and aerobic treatment systems can lead to satisfactory depuration levels before the effluents discharge to the surroundings. The authors also concluded that impinging-jet bubble column is an efficient and compact gas/liquid contacting system involving lower capital and operating costs. In fact, El-Din and Smith (2002) compared three types of ozone contactors on the ozonation of Kraft pulp mill effluents, namely, extra-coarse bubble diffuser, impinging-jet contactor and finebubble diffuser, and, even if similar depuration was attained, the impinging-jet contactor would require lower reactor volumes. Besides, an ozone off-gas destruction system would not be needed due to the ozone absorption capacity, reducing, thus, the capital and operating costs of ozonation.

According to Assalin et al. (2004a), ozonation was unable to completely mineralize Kraft $\mathrm{E}_{1}$ effluent (TOC removal of $20 \%$ ); however, this technology promoted high toxicity abatement (measured by Selenastrum capricornutum algal growth inhibition). The effect of ozone inlet concentration and $\mathrm{pH}$ was analyzed on the depuration of a similar wastewater (Assalin, et al. 2004b) and it was verified that the ozonation degradation rate was slower for $\mathrm{pH} 12$ when compared with $\mathrm{pH} 10$, which may be related with radical scavengers present in the liquid. High total phenolic content removal was observed and this parameter was not much affected by $\mathrm{pH}$. The ozone inlet concentration increase showed a positive effect over color, TPh and TOC abatement. Nevertheless, mineralization was always limited which confirms the difficult of single ozonation for TOC removal.

Medeiros et al. (2008) concluded that degradation of an alkaline bleach plant effluent was slightly inhibited when ozonation was carried out at $\mathrm{pH} 12$ when compared with $\mathrm{pH}$ 7. This seems somehow contradictory with the fact that at elevated $\mathrm{pH}$ values ozone decomposition is enhanced leading to hydroxyl radicals that are more reactive than molecular ozone. Thus, these points out that recalcitrant and color causing compounds with higher affinity with ozone are present in the effluent. Besides, the cumbersome composition of these wastewaters may encompass radical scavenger compounds which will reduce $\mathrm{HO}^{\bullet}$ action over organic matter. Still, an improvement on the wastewater biodegradability was attained, which was attributed to the cleavage of high molecular weight compounds. Similar results were reached by Kreetachat et al. (2007) on the ozonation of biologically treated pulp and paper mill wastewater with $\mathrm{BOD}_{5} / \mathrm{COD}$ increasing with treatment time.

With these results it seems advisable to integrate ozonation with biological treatment systems since chemical oxidation promotes biodegradability. In this ambit, Bijan and Mohseni (2005) analyzed the sequential ozonation/biological treatment of an effluent coming from an alkaline bleach plant. Ozonation promoted $\mathrm{BOD}_{5} / \mathrm{COD}$ increase which was endorsed due to the cleavage of high molecular weight to low molecular weight compounds more amenable to microorganisms. Biodegradability enhancement was higher when alkaline conditions were used. The integration between ozonation and aerobic digestion improved TOC removal in $30 \%$ when compared with the individual treatment systems.

Akmehmet Balcioglu et al. (2006) analyzed the effect of pre-ozonation on the biodegradation of bleached Kraft mill effluent by activated sludge and algal treatment. The $\mathrm{pH}$ increase slightly improved ozonation performance regarding COD and AOX abatement with $41 \%$ and $57 \%$ of removal for pH 7 and $50 \%$ and $61 \%$ of degradation at pH 12. However, this parameter had no noticeable impact over the efficiency of the subsequent biological system.

The highest COD and AOX abatements were attained when ozonation ( $\mathrm{pH} \mathrm{7)}$ was used prior to the application of an activated sludge reactor $(90 \%$ and $87 \%$ depletion, respectively). Moraes et al. (2006) submitted a Kraft E1 effluent and black liquor to integrated strategies involving ozonation and biological treatments. Single ozonation led to $30 \%$ and $10 \%$ of color removal of the Kraft effluent and black liquor. Nevertheless, TOC abatement was negligible in both streams. Biological oxidation by A. vinellandi led to $40 \%$ and $20 \%$ of mineralization of Kraft E1 effluent and black liquor, respectively. The use of an ozonation pre-treatment had almost negligible impact over TOC even if higher color removal was attained. Slightly better mineralization results were achieved when the biological system was used before ozonation with up to $50 \%$ and $30 \%$ of abatement (Kraft E1 and black liquor, respectively).

\section{Ozonation Aided by $\mathrm{UV} / \mathrm{H}_{2} \mathrm{O}_{2}$}

As already referred, besides alkaline conditions, ozone oxidant power can be enhanced by the presence of hydrogen peroxide and UV radiation that promotes $\mathrm{O}_{3}$ decomposition into the highly reactive and unselective hydroxyl radicals. With this aim, Freire et al. (2001) tested single ozonation (at $\mathrm{pH} 3$ and 11), $\mathrm{O}_{3}+\mathrm{H}_{2} \mathrm{O}_{2}$ and $\mathrm{O}_{3} / \mathrm{UV}$ on the degradation and toxicity removal of Kraft E1 effluent coming from a paper mill. Among the treatment systems tested, ozonation carried out at acidic $\mathrm{pH}$ was the less efficient since at those conditions only the direct ozone attack to the pollutants is possible.

All the other methodologies showed higher removal rates probably due to the formation of hydroxyl radicals. In this context, the best results regarding color abatement were 
attained by $\mathrm{O}_{3} / \mathrm{pH} 11 / \mathrm{UV}$ (up to $48 \%$ in $90 \mathrm{~min}$ ), whereas $\mathrm{TPh}$ was more efficiently degraded by $\mathrm{O}_{3} / \mathrm{pH} 11$ (nearly $90 \%$ in $90 \mathrm{~min}$ ). However, in any case significant TOC removal was attained (the maximum value was $10 \%$ for $\mathrm{O}_{3} / \mathrm{pH} 11$ and $\left.\mathrm{O}_{3} / \mathrm{pH} 11 / \mathrm{UV}\right)$. An important feature of these technologies is that they were able to reduce the effluents toxicity (measured by inhibition of $E$. coli respiration) especially for the two referred systems. Moreover, both processes showed low oxidation index which is defined as the ratio of ozone consumed to the percentage of color, TPh and TOC removal. This means that these treatments involve lower ozone doses for the effluents treatment $\left(225 \mathrm{mgO}_{3} / \mathrm{L}\right.$ when compared with $375 \mathrm{mgO}_{3} / \mathrm{L}$ required by $\mathrm{O}_{3} / \mathrm{H}_{2} \mathrm{O}_{2}$ ), which is economically preferable. In fact, ozone in situ generation is one of the most important drawbacks in this technology.

To enhance TOC removal of a pulp and paper effluent by the $\mathrm{O}_{3} / \mathrm{UV}$ process, Pérez et al. (2002) tested the impact of the addition of iron ions $\left(\mathrm{Fe}^{2+}\right)$, which will act as homogeneous catalyst. The maximum TOC removal was about $90 \%$ in $300 \mathrm{~min}$ of reaction. In order to minimize costs (related with ozone generation and UV lamp operation) several treatment sequences were tested involving: ozonation under UV irradiation throughout all the experiment; ozonation under UV radiation in the presence of $\mathrm{Fe}^{2+} ; 1 \mathrm{~h}$ stirred with $\mathrm{Fe}^{2+}$ without irradiation followed by $4 \mathrm{~h}$ of ozonation under UV radiation in the presence of $\mathrm{Fe}^{2+} ; 2 \mathrm{~h}$ stirred with $\mathrm{Fe}^{2+}$ without irradiation followed by $3 \mathrm{~h}$ of ozonation under $\mathrm{UV}$ radiation in the presence of $\mathrm{Fe}^{2+} ; 2 \mathrm{~h}$ stirred with $\mathrm{Fe}^{2+}$ under irradiation followed by $3 \mathrm{~h}$ of ozonation under UV radiation in the presence of $\mathrm{Fe}^{2+}$ and $3 \mathrm{~h}$ stirred with $\mathrm{Fe}^{2+}$ without irradiation followed by $2 \mathrm{~h}$ of ozonation under UV radiation in the presence of $\mathrm{Fe}^{2+}$. It was concluded that previous irradiation of the effluent in the presence of iron improved TOC removal. Moreover, up to $50 \%$ of reduction in the operating costs was attained when this irradiation period reached $2 \mathrm{~h}$. Higher economical safes were possible when $3 \mathrm{~h}$ of pretreatment were applied but a decrease of $10 \%$ on TOC removal was detected.

Sevimli (2005) concluded that both single ozonation and ozone combined with hydrogen peroxide enabled high color and aromatic content removal of a postbiologically (anaerobic + aerobic biological treatment plant) treated wastewater from pulp and paper industry. The presence of hydrogen peroxide yield higher COD removal (64\% against the $43 \%$ reached by the single process) besides reducing the reaction time for the same ozone dosages which will imply a lower energetic consumption with the ozone generator.

pH 7 showed to be the best $\mathrm{pH}$ condition to carry out ozonation of a pulp and paper industry effluent coming from a biological treatment plant (Catalkaya and Kargi 2007). Almost complete color removal was obtained whichever the $\mathrm{pH}$ used (3, 7 and 11). However, the best TOC and AOX degradation was observed for neutral conditions (29\% and $62.4 \%$, respectively). The increase on ozone feeding rate showed negligible impact over TOC and color removal; but higher AOX depuration was detected with up to $80.2 \%$ depletion for $11.9 \mathrm{gO}_{3} / \mathrm{h}$.
Hydrogen peroxide was added aiming to improve ozonation ability to mineralize the wastewater since, as referred before, this reactant is able to promote the formation of the highly reactive hydroxyl radicals. In this case it was verified that the highest $\mathrm{pH}$ values were more suitable to promote TOC removal, thus $\mathrm{pH} 11$ was selected to analyze the effect of $\left[\mathrm{H}_{2} \mathrm{O}_{2}\right]$. Even at high hydrogen peroxide dosage, it was concluded that no significant improvement was attained by using this combined treatment system regarding color and TOC removal. It should be though had into account the fact that $\mathrm{H}_{2} \mathrm{O}_{2}$ is unstable at alkaline conditions decomposing into water and oxygen that will be useless in the oxidation process, so other $\mathrm{pH}$ values should have been tested to analyze the impact of the co-oxidant in ozonation.

\section{Catalytic Ozonation}

Ozone is able to react with a wide range of organic compounds present in pulp and paper effluents, encompassing high electronic density groups such as color causing compounds, AOX, lignins, chloropehnolic, resin and fatty acids (Fontanier et al. 2005). Nevertheless, the mineralization is generally limited. In this context, ozone action can be enhanced by the presence of a suitable solid catalyst. Fontanier et al. (2005, 2006), analyzed catalytic ozonation according to the TOCCATA ${ }^{\circledR}$ process which was developed aiming to enhance ozone action over pollutants promoting mineralization (Baig et al. 2005).

The heterogeneous catalysts are based on metal oxides and can be shaped according to the reactors configuration (Baig et al. 2005). Ozonation was capable of almost completely mineralizing an effluent coming from a secondary biological treatment of a Kraft pulp mill; however, very low ozone consumption yield was observed (below 6\%); besides, some organic matter was detected to be removed by precipitation during the process. Contrary, with catalytic ozonation it was possible to reach similar depuration levels but involving better ozone usages. Fontanier et al. (2006) analyzed single and catalytic ozonation on the depuration of three different effluents (printing/writing paper, corrugated board and bleached sulfate pulp for printing papers) coming from secondary biological treatment plants at the mills.

It was concluded that contrarily to the single process, catalytic ozonation did not depend much on the effluents quality leading to continuous mineralization of organic matter with efficiency being independent of the inlet effluent characteristics. Thus, while ozonation allowed COD abatements of $36-76 \%$, the application of the solid catalyst improved these results to $53-72 \%$. It seems thus that the TOCCATA $^{\circledR}$ catalytic system has interesting features to be applied on the degradation of pulp and paper mill wastewaters.

Balcioglu et al. (2007) studied the impact of single and catalytic ozonation (over granular activated carbon - GAC) on the biodegradability enhancement of pulp mill effluents in order to enable a proper algal post-treatment. The presence of the catalyst improved COD (from $23 \%$ to $46 \%$ ) and color 
removal (from $74 \%$ to $87 \%$ ). Even if both single and catalytic processes were able to diminish toxicity, catalytic ozonation reduced the treatment time required to achieve a non-toxic effluent. The biodegradability enrichment was attributed to the decrease on the high molecular weight compounds content (which cannot penetrate through the cell membranes) and AOX concentration.

With these results, ozonation seems to be a promising technology on the pollution control of the complex effluents coming from pulp and paper mills. In fact, Kaindl and Liechti (2008) report interesting results of a full-scale ozonation reactor operating at a paper mill in Austria. The authors reveal that with this system COD removal can be automatically regulated to the desired value. The main disadvantage is related with ozone production costs. However, ozone demand can be minimized by integrating the chemical treatment with biofiltration. Besides, the application of suitable heterogeneous catalytic materials may render ozonation into a more competitive process.

\section{Other Agro-Industrial Wastewaters}

Here the application of ozonation on the depuration of other real agro-industrial wastewaters such as cork processing, tomato and cheese production will be reviewed (Table 4). Mediterranean Sea countries, especially Portugal and Spain, are the main world cork producers. Cork is used in a wide range of sectors; however, its main and most profitable application is the production of cork stoppers for wine bottles (Lan et al. 2008a). Cork processing involves boiling in water in order to improve its mechanical properties and remove some undesirable compounds that can interfere with the organoleptic characteristics of the wine.

The water used in this procedure has to be renewed after some batch due to the accumulation of substances such as phenolic acids and tannins leading to an effluent with dark color (Benitez et al. 2003). The presence of such toxic and bio-refractory compounds compromises the application of biological treatment systems (Lan et al. 2008a). In this ambit, ozonation can play an important role due to the high reactivity of ozone towards unsaturated pollutants.

Lan et al. (2008b) analyzed the impact of ozonation on the degradation of cork processing wastewater after one and 20 cork boiling batches at their natural $\mathrm{pH}$ (6.45) aiming to avoid costs to perform $\mathrm{pH}$ adjustments. High COD and TOC removals were observed for these effluents leading to up to $90 \%$ of degradation within 120 min demonstrating the potential of ozonation for water recycling and reuse in cork processing industry. $\mathrm{pH}$ was followed up during the process and it was observed a decrease at the beginning of the reaction due to the formation of carboxylic acids as by-products. In a second step, $\mathrm{pH}$ raises due to the mineralization of those intermediates. It was concluded that most part of the degradation occurred for $\mathrm{pH}$ values below 5.5 which means that direct ozone reactions were the main responsible for the depuration.
Acero et al. (2004) tested the treatment of cork processing wastewater by single ozone and ozone aided by hydrogen peroxide or/and UV radiation. In what regards single ozonation the impact of ozone inlet partial pressure $(1.43-4.45 \mathrm{kPa})$ and temperature $\left(20-60{ }^{\circ} \mathrm{C}\right)$ was studied and both parameters had a positive impact in the removal of TPh and COD. In fact, ozone by itself was able to promote COD abatements within the range 42.1-75.7\% leading, this way, to streams able to be reused. The presence of hydrogen peroxide improved the process efficiency with slightly increased depuration for higher hydrogen peroxide concentrations.

Almost complete COD depletion (97.8\%) was attained when ozone action was enhanced by UV radiation. The best results (up to $98.2 \%$ of COD removal) were verified by the conjugation $\mathrm{O}_{3} / \mathrm{H}_{2} \mathrm{O}_{2} / \mathrm{UV}$. The higher abatement yields reached with these combined systems were attributed to the generation of hydroxyl radicals due to the presence of $\mathrm{H}_{2} \mathrm{O}_{2}$ and UV, which promote the decomposition of substances refractory to the action of molecular ozone. Lan et al. (2008a) suggest the industrial application of ozonation aided by hydrogen peroxide in the initial depuration times until the total removal of color of the cork processing wastewater; afterwards the stream should be subjected to $\mathrm{O}_{3} / \mathrm{UVC}$ process for final treatment.

Benitez et al. (2003) concluded that, to accomplish the legal thresholds for wastewater discharge throughout the natural water courses, it would be required to use high ozone doses or hydraulic retention times in the ozonation of cork processing effluents. The introduction of $\mathrm{H}_{2} \mathrm{O}_{2}$ or UV enhanced ozone action over the pollutants due to the formation of hydroxyl radicals. However, for the experimental conditions applied (Table 4) the treated effluents COD was still above the permitted limits for disposal. The stream $\mathrm{BOD}_{5}$ values were determined along the reaction and it was concluded that biodegradability increased along the ozonation time probably due to the high degradation of $\mathrm{TPh}$. This means that the remaining pollutants can be easily degraded by aerobic biological means. Thus, the integration between ozonation and activated sludge $\left(\mathrm{O}_{3}+\right.$ aerobic treatment and aerobic treatment $+\mathrm{O}_{3}$ ) was analyzed.

Overall degradations higher than the single processes were achieved in both schemes used, but the best results were attained for the case where ozonation was applied after the aerobic treatment stage. In fact, from the kinetic studies performed it was concluded that the biological pre-treatment improved ozonation reaction rate leading to higher rate constants in this case. It should be noted that the stream resulting from this treatment methodology was within the limits for direct discharge towards the water-courses. Besides, the required ozonation hydraulic retention time was shorter ( $3 \mathrm{~h}$ when compared with the $6 \mathrm{~h}$ needed in the case where ozonation was followed by aerobic treatment) which is industrially preferable.

With the aim of water reuse and/or discharge throughout the natural water streams, Benitez et al. (2008) analyzed 
TABLE 4. Summary of the Applications of Ozonation for the Treatment of Cork, Tomato and Milk Processing Industries Wastewaters

\begin{tabular}{|c|c|c|c|}
\hline Wastewater Characteristics & Operating Conditions & Main results & Reference \\
\hline $\begin{array}{l}\text { Cork processing wastewater: } \\
\mathrm{COD}_{0}=1.6 \mathrm{~g} \mathrm{~L}^{-1} ; \mathrm{BOD}_{50}= \\
0.75 \mathrm{~g} \mathrm{~L}^{-1} ; \mathrm{TPh}_{0}= \\
305 \mathrm{mg} \mathrm{L}^{-1} ; \mathrm{TSS}_{0}= \\
0.12 \mathrm{~g} \mathrm{~L}^{-1} \mathrm{pH}=4 \text {. } \\
\text { The effluent was centrifuged } \\
\text { and filtered }\end{array}$ & $\begin{array}{l}\mathrm{T}=20-60{ }^{\circ} \mathrm{C} \\
\mathrm{pO}_{3}=1.43-4.45 \mathrm{kPa} ; \\
{\left[\mathrm{H}_{2} \mathrm{O}_{2}\right]=0-0.1 \mathrm{M}} \\
\text { TQ } 150 \text { high pressure mercury } \\
\quad \text { lamp }(\lambda=185-436 \mathrm{~nm}) 150 \mathrm{~W} \\
\quad 1.76 \times 10^{-5} \text { Einstein } / \mathrm{s}\end{array}$ & $\begin{array}{l}\mathrm{O}_{3}: \\
\mathrm{X}_{\mathrm{COD}}=42.1-75.7 \% \\
\mathrm{X}_{\mathrm{TPh}}=80.4-99.2 \% \\
\mathrm{O}_{3} / \mathrm{H}_{2} \mathrm{O}_{2}: \\
\mathrm{X}_{\mathrm{COD}}=76.3-79.8 \% \\
\mathrm{X}_{\mathrm{TPh}}=95.2-97.7 \% \\
\mathrm{O}_{3} / \mathrm{UV}: \\
\mathrm{X}_{\mathrm{COD}}=97.8-97.9 \% \\
\mathrm{X}_{\mathrm{TPh}}=98.9-100 \% \\
\mathrm{O}_{3} / \mathrm{H}_{2} \mathrm{O}_{2} / \mathrm{UV}: \\
\mathrm{X}_{\mathrm{COD}}=98.2 \% \\
\mathrm{X}_{\mathrm{TPh}}=99.5 \%\end{array}$ & $\begin{array}{l}\text { Acero et al. } \\
\text { 2004) }\end{array}$ \\
\hline $\begin{array}{l}\text { Cork processing wastewater: } \\
\mathrm{COD}_{0}=1.9 \mathrm{~g} \mathrm{~L}^{-1} ; \mathrm{BOD}_{50}= \\
1.15 \mathrm{~g} \mathrm{~L}^{-1} ; \mathrm{TPh}_{0}= \\
0.29 \mathrm{~g} \mathrm{~L}^{-1} ; \mathrm{pH}=5.4\end{array}$ & $\begin{array}{l}\mathrm{Q}_{\mathrm{gas}}=50 \mathrm{~L} / \mathrm{h} ; \mathrm{pO}_{3}= \\
0.40-2.98 \mathrm{kPa} ; \mathrm{pH}=5.35 ; \mathrm{T}= \\
20{ }^{\circ} \mathrm{C} ;\left[\mathrm{H}_{2} \mathrm{O}_{2}\right] /\left[\mathrm{O}_{3}\right]=0.5 \\
(\mathrm{~mol} / \mathrm{mol}) . \\
700 \mathrm{~W} \text { medium pressure mercury } \\
\quad \text { vapor lamp }(\lambda \approx 185 \mathrm{~nm})\end{array}$ & $\begin{array}{l}\mathrm{O}_{3}: \\
\mathrm{X}_{\mathrm{COD}}=12-54 \% \\
\mathrm{X}_{\mathrm{TPh}}=65-81 \% \\
\mathrm{O}_{3} / \mathrm{H}_{2} \mathrm{O}_{2}: \\
\mathrm{X}_{\mathrm{COD}}=51 \% \\
\mathrm{X}_{\mathrm{TPh}}=80 \% \\
\mathrm{O}_{3} / \mathrm{UV}: \\
\mathrm{X}_{\mathrm{COD}}=50 \% \\
\mathrm{X}_{\mathrm{TPh}}=85 \% \\
\mathrm{Activated} \mathrm{sludge:} \\
\mathrm{X}_{\mathrm{COD}}=13-37 \% \\
\mathrm{X}_{\mathrm{TPh}}=20-32 \% \\
\mathrm{O}_{3}+\text { Activated sludge: } \\
\mathrm{X}_{\mathrm{COD}}=65 \% \\
\mathrm{X}_{\mathrm{TPh}}=94 \% \\
\text { Activated sludge }+\mathrm{O}_{3}: \\
\mathrm{X}_{\mathrm{COD}}=77 \% \\
\mathrm{X}_{\mathrm{TPh}}=92 \%\end{array}$ & $\begin{array}{l}\text { (Benitez et al. } \\
\text { 2003) }\end{array}$ \\
\hline $\begin{array}{l}\text { Cork processing wastewater: } \\
\mathrm{COD}_{0}=4.40 \mathrm{~g} \mathrm{~L}^{-1} ; \mathrm{BOD}_{50}= \\
1.75 \mathrm{~g} \mathrm{~L}^{-1} ; \text { Tannins } \\
\text { content }_{0}=0.897 \mathrm{~g} \mathrm{~L}^{-1} ; \\
\mathrm{TSS}_{0}=0.28 \mathrm{~g} \mathrm{~L}^{-1} ; \mathrm{pH}=4.7\end{array}$ & $\begin{array}{l}\mathrm{Q}_{\mathrm{gas}}=40 \mathrm{~L} / \mathrm{h} ; \mathrm{pO}_{3}=4.7 \mathrm{kPa} ; \\
\operatorname{tr}=6 \mathrm{~h} ;\left[\mathrm{H}_{2} \mathrm{O}_{2}\right]=1 \times 10^{-3} \mathrm{M} \\
150 \mathrm{~W} \text { medium pressure mercury } \\
\quad \text { vapor lamp }(\lambda \approx 185-436 \mathrm{~nm})\end{array}$ & $\begin{array}{l}\mathrm{O}_{3}: \\
\mathrm{X}_{\mathrm{COD}}=39.3 \% \\
\mathrm{X}_{\text {Tannins }}=78.1 \% \\
\mathrm{UF}: \\
\mathrm{X}_{\mathrm{COD}}=6.6-29.4 \% \\
\mathrm{X}_{\text {Tannins }}=15.9-41.3 \%\end{array}$ & $\begin{array}{l}\text { (Benítez et al. } \\
\text { 2008) }\end{array}$ \\
\hline
\end{tabular}

(Continued) 
TABLE 4. (Continued)

\begin{tabular}{|c|c|c|c|}
\hline Wastewater Characteristics & Operating Conditions & Main results & Reference \\
\hline \multirow[t]{7}{*}{$\begin{array}{l}\text { The effluent was filtrated to } \\
\text { remove suspended solids }\end{array}$} & & $\begin{array}{l}\mathrm{O}_{3}+\mathrm{UF}: \\
\mathrm{X}_{\mathrm{COD}}=42.1-57.5 \% \\
\mathrm{X}_{\text {Tannins }}=82.0-86.2 \%\end{array}$ & \\
\hline & & $\begin{array}{l}\mathrm{O}_{3} \text { after UF: } \\
\mathrm{X}_{\mathrm{COD}}=74.8-80.4 \% \\
\mathrm{X}_{\text {Tannins }}=90.8-96.5 \%\end{array}$ & \\
\hline & & $\begin{array}{l}\mathrm{UF}+\mathrm{O}_{3} \text { (globally): } \\
\mathrm{X}_{\mathrm{COD}}=82.4-89.8 \% \\
\mathrm{X}_{\text {Tannins }}=93.5-98.4 \%\end{array}$ & \\
\hline & & $\begin{array}{l}\mathrm{O}_{3} / \mathrm{UV} \text { after UF: } \\
\mathrm{X}_{\mathrm{COD}}=97.2 \% \\
\mathrm{X}_{\text {Tannins }}=100 \%\end{array}$ & \\
\hline & & $\begin{array}{l}\mathrm{UF}+\mathrm{O}_{3} / \mathrm{UV} \text { (globally): } \\
\mathrm{X}_{\mathrm{COD}}=99.6 \% \\
\mathrm{X}_{\text {Tannins }}=100 \%\end{array}$ & \\
\hline & & $\begin{array}{l}\mathrm{O}_{3} / \mathrm{H}_{2} \mathrm{O}_{2} \text { after UF: } \\
\mathrm{X}_{\mathrm{COD}}=99.4 \% \\
\mathrm{X}_{\text {Tannins }}=100 \%\end{array}$ & \\
\hline & & $\begin{array}{c}\mathrm{UF}+\mathrm{O}_{3} / \mathrm{H}_{2} \mathrm{O}_{2} \\
\quad \text { (globally): } \\
\mathrm{X}_{\mathrm{COD}}=98.2 \% \\
\mathrm{X}_{\text {Tannins }}=100 \%\end{array}$ & \\
\hline Tomato wastewater & $\begin{array}{l}\mathrm{G}_{\mathrm{O}_{3}}=25.3 \mathrm{mg} \mathrm{min}-1 \\
{\left[\mathrm{H}_{2} \mathrm{O}_{2}\right]=10^{-3}-0.02 \mathrm{M}} \\
\text { UV radiation: } 3.8 \times 10^{-6} \\
\quad \text { Einstein/(L.s) }\end{array}$ & $\begin{array}{l}\mathrm{O}_{3}: \\
\mathrm{X}_{\mathrm{COD}}=30-50 \% \\
\mathrm{O}_{3} / \mathrm{H}_{2} \mathrm{O}_{2} \\
\mathrm{X}_{\mathrm{COD}}=26-86 \% \\
\mathrm{O}_{3} / \mathrm{UV}: \\
\mathrm{X}_{\mathrm{COD}}=90 \%\end{array}$ & (Beltrán et al. 1997) \\
\hline \multirow{4}{*}{$\begin{array}{l}\text { Postbiologically treated milk } \\
\text { whey wastewater: } \\
\mathrm{COD}_{0}=520 \mathrm{mg} \mathrm{L}^{-1} ; \mathrm{BOD}_{0}= \\
151 \mathrm{mg} \mathrm{L}^{-1} ; \mathrm{TOC}_{0}= \\
215 \mathrm{mg} \mathrm{L}^{-1}\end{array}$} & \multirow{4}{*}{$\begin{array}{l}\text { Catalyst: } \mathrm{Mn}-\mathrm{Ce}-\mathrm{O} ; \mathrm{Fe}-\mathrm{Mn}-\mathrm{O} \\
\mathrm{C}_{\mathrm{Cat}}=10 \mathrm{~g} \mathrm{~L}^{-1} \\
C_{O_{3}}^{\text {inlet }}=10 \mathrm{~g} \mathrm{~m}^{-3} \\
\mathrm{Q}_{\mathrm{gas}}=500 \mathrm{~mL} \mathrm{~min}^{-1} \\
\mathrm{pH}=2-10 \\
{\left[\mathrm{H}_{2} \mathrm{O}_{2}\right]=16.5-66.0 \mathrm{mM}}\end{array}$} & $\begin{array}{l}\text { Single ozonation } \\
\mathrm{X}_{\mathrm{COD}}=23-63 \%\end{array}$ & \multirow{4}{*}{$\begin{array}{l}\text { (Martins and } \\
\text { Quinta-Ferreira } \\
\text { 2010) }\end{array}$} \\
\hline & & $\begin{array}{l}\text { Catalytic ozonation } \\
(\mathrm{Mn}-\mathrm{Ce}-\mathrm{O}) \\
\mathrm{X}_{\mathrm{COD}}=70 \%\end{array}$ & \\
\hline & & $\begin{array}{l}\text { Catalytic ozonation } \\
(\mathrm{Fe}-\mathrm{Mn}-\mathrm{O}) \\
\mathrm{X}_{\mathrm{COD}}=66 \%\end{array}$ & \\
\hline & & $\begin{array}{l}\text { Ozonation }+\mathrm{H}_{2} \mathrm{O}_{2} \\
\mathrm{X}_{\mathrm{COD}}=42-100 \%\end{array}$ & \\
\hline
\end{tabular}

ozonation and its integration with membrane processes for the treatment of cork processing wastewater. With an initial effluent encompassing a COD of $4.40 \mathrm{~g} \mathrm{~L}^{-1}$, single ozonation was able to remove up to $39.3 \%$ of COD and almost the totally of the effluents tannic content $(78.1 \%)$ and color. The moderate COD removal in comparison to the other parameters is related with the presence of substances refractory to the direct attack of ozone. The application of a posterior ultra filtration (UF) stage led to a global COD removal within the range of $42-57.5 \%$. Ozonation effectiveness was truly improved when the effluent was previously subjected to UF; in fact, in this case $\mathrm{O}_{3}$ was able to remove between $74.8-80.4 \%$ of COD 
(when compared with the $42-57.5 \%$ attained when ozonation was followed by UF). Globally $\mathrm{O}_{3}+$ UF led to 82.9-89.8\% of COD abatement. Moreover, when $\mathrm{O}_{3} / \mathrm{H}_{2} \mathrm{O}_{2}$ or $\mathrm{O}_{3} / \mathrm{UV}$ was applied to the effluent previously submitted to UF, almost totally COD removal was observed with degradations up to $98.2 \%$ and $99.6 \%$, respectively. With these results, it seems that UF followed by $\mathrm{O}_{3} / \mathrm{H}_{2} \mathrm{O}_{2}$ or $\mathrm{O}_{3} / \mathrm{UV}$ is able to lead to a treated cork processing wastewater with characteristics that enable its discharge to the natural water courses or to be reused in the same industrial plant. Besides the application of separation technologies can somehow open the door for the recovery of some valuable products from the wastewater.

Ozonation aided by hydrogen peroxide was very efficient on the decrease of COD of a tomato processing industry (Beltrán et al. 1997) with up to $86 \%$ of COD elimination when compared with the $50 \%$ achieved by single ozonation. The increase on $\mathrm{H}_{2} \mathrm{O}_{2}$ concentration improves COD degradation; however, for $2 \times 10^{-2} \mathrm{M}$, COD removal was inhibited probably due to the radical scavenger effect of this reactant when in excess. Also the combination between ozone and UV radiation was able to deplete $90 \%$ of COD.

Assalin et al. (2004) concluded that ozonation was inadequate to directly remediate cheese whey. Cheese industry produces large amounts of milk whey (up to $90 \mathrm{~kg}$ per $20 \mathrm{~kg}$ of cheese (Madaeni and Mansourpanah 2004). These streams encompass large amounts of COD; nevertheless, due to its richness in nutrients such as lactose, proteins and mineral salts, the biological treatments are, generally, very efficient on their depuration. Nonetheless, in some situations, the activated sludge reactors are not able to fulfil the legal thresholds for the effluent direct discharge throughout the natural resources.

In this ambit, our research group addressed a milk whey effluent coming from a bio-reactor which still was outside the proper limits (Martins and Quinta-Ferreira 2010) with a COD of $520 \mathrm{mg} / \mathrm{L}$ (above the $150 \mathrm{mg} / \mathrm{L}$ allowed by Portuguese legislation). Thus, the goal was to indicate the most suitable methodology to further refine the stream. Single ozonation was tested at different $\mathrm{pH}$ values and, even if the $\mathrm{pH}$ increase improved COD removal (with up to $63 \%$ of COD degraded for $\mathrm{pH} 10$ ), the resulting wastewater was yet outside the limits for discharge. Trying to improve ozone action over the pollutants, the solid catalyst $\mathrm{Mn}-\mathrm{Ce}-\mathrm{O}$ and $\mathrm{Fe}-\mathrm{Mn}-\mathrm{O}$, previously selected as potentially actives for the depuration of OMW (Martins and Quinta-Ferreira 2010) were tested for this effluent. Although the high COD abatements attained, the recovered solids presented high amounts of carbon adsorbed into their surface which may block the access of the reactants to the active sites compromising the catalyst stability for several reuses. In this context, it would be industrially unviable to implement such treatment since constant substitution of the catalyst would be required. This highlights the need of performing laboratory studies for each type of effluent since totally different results may be attained for the same catalyst when applied on the depuration of different wastewaters. In fact, it should be reminded the high efficiency of these materials when applied to OMW (Martins and Quinta-Ferreira 2011a).

Within these results, the possibility of enhancing ozone reaction by the introduction of hydrogen peroxide as cooxidant was investigated. A high COD removal was observed when low concentrations of $\mathrm{H}_{2} \mathrm{O}_{2}$ were applied with total COD depletion achieved in $420 \mathrm{~min}$ for $\left[\mathrm{H}_{2} \mathrm{O}_{2}\right]=33.0 \mathrm{mM}$. The further increase on the hydrogen peroxide load revealed to have an inhibitory effect for pollutants oxidation by this process which can be attributed to the radical scavenger ability of this reactant when in excess. Moreover, eco-toxicological analysis based on the luminescence inhibition of Vibrio fischery showed that the treated water did not present negative impact over the ecosystems. Thus, it seems advisable to refine the post-biological milk whey effluent by ozonation aided by hydrogen peroxide at low concentrations.

\section{CONCLUSIONS AND FUTURE PERSPECTIVES}

The structure of the present review, focusing ozonation as an alternative chemical treatment for agro-effluents streams, covers different processes reported in the specialized literature, starting, in each case, with single operation results, followed by the recourse to co-oxidant aided systems with light and $\mathrm{H}_{2} \mathrm{O}_{2}$. Finally, integration strategies and catalytic technologies are highlighted.

Table 5 summarizes the main characteristics of the different agro-industrial wastewaters revised in this article. As it can be observed, these streams may present a wide range of pollutant loads. Indeed, the ratios between the highest and lowest COD values reported by the literature studies for the same effluent group can diverge within a large spectrum of values, namely, 13 for cork industry-(4400/350), 27 for pulp and paper wastewaters $(1859 / 70), 47$ for olive processing

TABLE 5. Overview of the Agro-industrial Wastewaters Characteristics

\begin{tabular}{lccc}
\hline Effluents & $\mathrm{COD}_{0}\left(\mathrm{mgO}_{2} \mathrm{~L}^{-1}\right)$ & $\mathrm{TPh}_{0}\left(\mathrm{mg} \mathrm{L}^{-1}\right)$ & $\mathrm{BOD}_{0}\left(\mathrm{mgO}_{2} \mathrm{~L}^{-1}\right)$ \\
\hline Olive processing effluents & $2900-134100$ & $43-2100$ & $650-52,000$ \\
Winery and distillery wastewaters & $522-62000$ & $28-134$ & $4.6-13$ \\
Pulp and paper wastewaters & $70-1859$ & $27-35.2$ & $3.7-5.3$ \\
Cork Processing industry wastewaters & $350-4400$ & $290-305$ & $9.1-282$ \\
Post-biologically treated milk whey wastewater & 520 & - & $750-1750$ \\
\hline
\end{tabular}




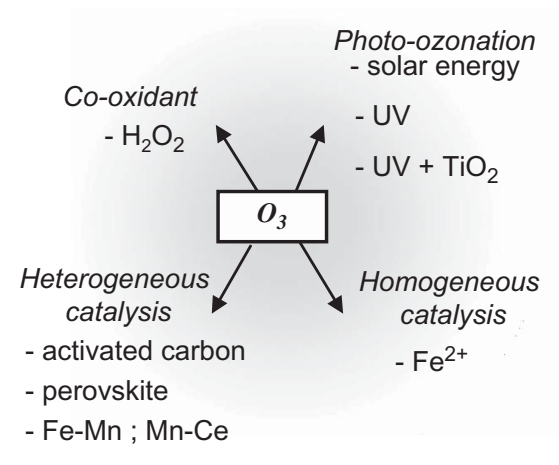

a)

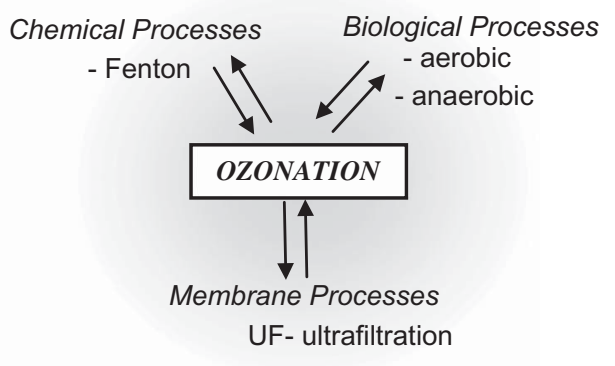

b)

FIGURE 1. Ozone-based technologies (a) and integrated schemes involving ozonation (b) applied on the treatment of actual agro-industrial wastewaters.

effluents $(134,100 / 2900)$, up to 119 for winery and distillery plants $(62,000 / 522)$ reflecting the strong differences found for the same kind of wastewater which usually are not highlighted in literature, not allowing a proper comparison between the results attained by different research groups.

The results collected in this review show that the several ozone based depuration techniques (Figure 1a) including, besides single $\mathrm{O}_{3}$ processes, the application of co-oxidants and photo-aided systems aside catalytic ozonation, either homogenous or heterogeneous, can be interesting alternatives to the inefficient traditional biological methodologies. Furthermore, different treatment schemes (Figure 1b) integrating ozonation with chemical, biological and membrane processes can be relevant candidate technologies in order to reach cost/effective treatments.

The diversity of the published results due to the significant variations on the effluents compositions do not permit to propose a universal strategy based on ozone to manage such a wide spectrum of cumbersome wastewaters. In this ambit, research is compulsorily required for each specific case aiming to provide stakeholders with reliable strategies to their particular problem.

Generally speaking, it seems advisable to integrate this chemical oxidation system with biological reactors, since, while ozone is able to cleave bio-refractory compounds, biodegradable substances are more efficiently removed by microorganism at lower operating costs.

The introduction of hydrogen peroxide or/and UV radiation enhances hydroxyl radicals production which are able to react with a wider range of compounds. However, in some cases, the presence of radical scavenger substances in the real effluent composition may inhibit oxidation. The recourse to sequential schemes promoting some stages of direct ozone attack and others involving radicalar pathways may be important to avoid such shortcoming.

In what regards mechanistic and engineering aspects of ozonation, to the best of our knowledge, only two industrial in-situ applications of these technologies are reported in specialized literature for the treatment of agro-industrial wastewaters. Based on our research, our spin-off Adventech built up an olive mill effluents treatment plant integrating Fenton's process with single ozonation. In this unit designed to treat a $48 \mathrm{~m}^{3}$ daily flow, the previously coagulated/ flocculated polluted stream is oxidized during $1 \mathrm{~h}$ in a Fenton's stirred reactor and conducted to an ozonation tank. According to the industrial results (Martins et al. 2010), at the end of this sequence, the treated effluent largely reaches the imposed legal limits to be discharged to the local sewage where it is successfully subjected to biological degradation on the municipal wastewater treatment plant due to its high biodegradability. Besides, according to the stakeholders the treatment cost is low, not exceeding $0.02 € / \mathrm{kg}$ of olive oil produced. Also, an industrial ozonation reactor for pulp and paper mills effluents treatment able to be regulated to comply with the variations on the inlet wastewater composition in order to assess the desired depuration efficiency is reported by Kaindl and Liechti (2008).

This overview reveals that ozone based technologies have interesting features to be further applied to treat agroindustrial wastewater at a full scale. The application of heterogeneous catalysts to enhance ozone action over pollutants has not being much explored to actual agro-effluents and may be an important point since the presence of suitable solid materials tends to improve ozone usage during the process, minimizing, this way, the amount of oxidant wasted in the reactors outlet gas stream. In fact, some heterogeneous catalysts were indicated as suitable for batch depuration of various agro-effluents such as olive mill; nevertheless, further studies are required concerning their lifetime and regeneration options so that industrial application may be feasible.

TOCCATA process efficiency on actual pulp and paper effluents pollutant character abatement is a strong encouragement to direct investigation towards catalytic ozonation. It is thus required to turn efforts on the application of catalytic 
ozonation for the depuration of actual effluents. In this view, it seems advisable to look for catalysts able to promote molecular ozone reactions that are less prone to the negative effect of the presence of radical inhibiting substances is some real wastewaters. Moreover, since, from an economical point of view, it is preferable to use firstly the chemical process to improve the effluents biodegradability recurring afterwards to an inexpensive biological treatment, special attention must be given to biodegradability and toxicity parameters.

Special care should be given to the catalytic materials stability involving leaching and carbon adsorption, since these phenomena are the main drawback associated to heterogeneous catalysis.It should be referred the need of performing pilot scale investigation to grasp the main features of this challenging treatment methodology when operating in a continuous mode giving thus a strong contribution for their effective industrial implementation supported on environmental catalysis. Also, it must be highlighted the lack of information regarding the costs associated with the purposed treatments that should be further discussed in forthcoming publications.

\section{FUNDING}

Fundação para a Ciência e Tecnologia (FCT) is gratefully acknowledged for the financial support under the Post-Doc grant (BPD/72200/2010) and the contract (PTDC/EQUERQ/113308/2009).

\section{REFERENCES}

Acero, J.L., F.J. Benítez, J. Beltran de Heredia, and A. Leal. 2004. "Chemical Treatment of Cork-Processing Wastewaters for Potential Reuse." Journal of Chemical Technology \& Biotechnology 79: 1065-1072.

Agustina, T.E., H.M. Ang, and V. Parek. 2008. "Treatment Of Winery Wastewater Using A Photocatalytic/Photolytic Reactor." Chemical Engineering Journal 135(1-2): 151-156.

Akmehmet Balcioglu, I., C. Sarac, C. Kivilcimdam, and E. Tarlan. 2006. "Application of Ozonation and Biotreatment for Forest Industry Wastewater." Ozone: Science \& Engineering 28(6): 431-436.

Alonso, J.B.d.H., J.T. Antón, J. Rodriguez, M. Viseas, and J. Vargas. 2000. "Tratamiento biológico aerobio de alpechín depurado previamente con ozono." Grasas y Aceites 51(5): 332-339.

Álvarez, P.M., F.J. Beltrán, F. Masa, and J. Pocostales. 2009. “A Comparison Between Catalytic Ozonation and Activated Carbon Adsorption/OzoneRegeneration Processes for Wastewater Treatment." Applied Catalysis B: Environmental 92(3-4): 393-400.

Álvarez, P.M., J.P. Pocostales, and F. Beltrán. 2011. "Granular activated carbon promoted Ozonation of a Food-Processing Secondary Effluent." Journal of Hazardous Materials 185(2-3): 776-783.

Andreozzi, R., M. Canterino, I. Somma, R. Giudice, R. Marotta, G. Pinto, and A. Pollio. 2008. "Effect of Combined Physico-Chemical Processes on the Phytotoxicity of Olive Mill Wastewaters." Water Research 42(6-7): 1684-1692.

Andreozzi, R., G. Longo, M. Majone, and G. Modesti. 1998. "Integrated Treatment of Olive Oil Mill Effluents (OME): Study of Ozonation Coupled with Anaerobic Digestion." Water Research 32(8): 2357-2364.

Assalin, M.R., E.S. Almeida, M. Rosa, S. Moraes, and N. Durán. 2004a. "Application of Ozonation Process In Industrial Wastewaters: Textile, Kraft E1 And Whey Effluents." Environmental Technology 25(8): $867-872$.
Assalin, M.R., M.A. Rosa, and N. Durán. 2004b. "Remediation of Kraft Effluent by Ozonation: Effect of Applied Ozone Concentration and Initial pH." Ozone: Science \& Engineering 26(3): 317-322.

Azbar, A., A. Bayram, A. Filibeli, A. Muezzinoglu, F. Sengul, and A. Ozer. 2004. "A Review of Waste Management Options in Olive Oil Production." Critical Reviews in Environmental Science and Technology 34:209-247.

Baig, S., C. Legay, J. Molinier, S. Escude, Y. Lucchese, and M. Dartguenave. Method for mineralization of organic pollutants in water by catalytic ozonation. French Patent WO. 99/65828 to Degrémont, filed December 4, 2000, and issued July 15, 2005.

Balcioglu, I., E. Tarlan, C. Kivillimdan, and M. Sagan (2007). "Merits of Ozonation and Catalytic Ozonation Pre-treatment in the Algal Treatment of Pulp and Paper Mill effluents." Journal of Environmental Management 85:918-926.

Bautista, P., A. Mohedano, J. Casas, J. Zazo, and J. Rodriguez. 2008. "An Overview of the Application of Fenton Oxidation to Industrial Wastewaters Treatment." Journal of Chemical Technology \& Biotechnology 83: 1323-1338.

Beltran-Heredia, J., J. Torregrosa, J. Dominguez, and J. Garcia. 2000a. "Aerobic Biological Treatment of Black Table Olive Washing Wastewaters: Effect of an Ozonation Stage." Process Biochemistry 35(10): 1183-1190.

Beltran-Heredia, J., J. Torregrosa, J. Dominguez, and J. Garcia. 2000b. "Treatment of Black-Olive Wastewaters by Ozonation and Aerobic Biological Degradation.” Water Research 34(14): 3515-3522.

Beltran de Heredia, J., J.R. Dominguez, and E. Partido. 2005. "Physicochemical Treatment for the Depuration of Wine Distillery Wastewaters (Vinasses)." Water Science \& Technology 51: 159-166.

Beltran de Heredia, J., and J. Garcia (2005). "Process Integration: Continuous Anaerobic Digestion Ozonation Treatment of Olive Mill Wastewater." Industrial \& Engineering Chemistry Research 44(23): 8750-8755.

Beltrán, F., J. Encinar, and J. González. 1997. "Industrial Wastewater Combined Advanced Oxidation. Part 2. Ozone Combined with Hydrogen Peroxide or UV Radiation." Water Research 31(10): 2415-2428.

Beltrán, F.J., J.F. García-Araya, and P. Álvarez. 2001. "pH Sequential Ozonation of Domestic and Wine-Distillery Wastewaters." Water Research 35(4): 929-936.

Beltrán, F.J., J.F. García-Araya, J. Frades, P. Álvarez, and O. Gimeno (1999). "Effects of Single and Combined Ozonation with Hydrogen Peroxide or UV Radiation on the Chemical Ddegradation and Biodegradability of Debittering Table Olive Industrial Wastewaters." Water Research 33(3): 723-732.

Benitez, F.J., J.L. Acero, J. Garcia, and A. Leal. 2003. "Purification of Cork Processing Wastewaters by Ozone, by Activated Sludge, and Their Two Sequential Applications." Water Research 37: 4081-4090.

Benitez, F.J., J.L. Acero, T. Gonzalez, and J. Garcia. 2001. "Ozonation and Biodegradation Processes in Batch Reactors Treating Black Olives Washing Wastewater." Industrial \& Engineering Chemistry Research 40: 3144-3151.

Benitez, F.J., J.L. Acero, T. Gonzalez, and J. Garcia. 2002. "The Use of Ozone, Ozone Plus UV Radiation, and Aerobic Microorganisms in the Purification of Some Agro-industrial Wastewaters." Journal of Environmental Science and Health, Part A A37(7): 1307-1325.

Benítez, F.J., J.L. Acero, A. Leal, and F. Real. 2008. "Ozone and Membrane Filtration Based Strategies for the Treatment of Cork Processing Wastewaters.” Journal of Hazardous Materials 152: 373-380.

Benitez, F.J., J. Beltran-Heredia, J. Torregrosa, and J. Acero. 1997. "Improvement of the Anaerobic Biodegradation of Olive Mill Wastewaters by Prior Ozonation Pretreatment." Bioprocess and Biosystems Engineering 17(3): 169-175.

Benitez, F. J., J. Beltran-Heredia, J. Torregrosa, and J. Dominguez. 1999. "Aerobic Treatment of Black Olive Wastewater and the Effect of an Ozonation Stage." Bioprocess and Biosystems Engineering 20(4): 355-361.

Benitez, F.J., F.J. Real, J. Acero, J. Garcia, and M. Sanchez (2003). "Kinetics of the Ozonation and Aerobic Biodegradation of Wine Vinasses 
in Discontinuous and Continuous Processes." Journal of Hazardous Materials 101: 203-218.

Bijan, L. and M. Mohseni (2005). "Integrated ozone and biotreatment of pulp mill effluent and changes in biodegradability and molecular weight distribution of organic compounds." Water Research 39(16): 3763-3772.

Braz, R., A. Pirra, M. Lucas, and J. Peres (2010). "Combination of Long Term Aerated Storage and Chemical Coagulation/Flocculation to Winery Wastewater Treatment." Desalination 263: 226-232.

Carbajo, M., F.J. Beltrán, O. Gimeno, B. Acedo, and F. Rivas (2007). "Ozonation of Phenolic Wastewaters in the Presence of a Perovskite Type Catalyst." Applied Catalysis B: Environmental 74(3-4): 203-210.

Carbajo, M., F. J. Beltrán, F. Medina, O. Gimeno, and F. Rivas. 2006. "Catalytic Ozonation of Phenolic Compounds: The Case of Gallic Acid." Applied Catalysis B: Environmental 67(3-4): 177-186.

Catalkaya, E.C., and F. Kargi. 2007. "Color, TOC and AOX Removals from Pulp Mill Effluent by Advanced Oxidation Processes: A Comparative Study." Journal of Hazardous Materials 139(2): 244-253.

Chedeville, O., M. Debacq, and C. Porte (2009). "Removal of Phenolic Compounds Present in Olive Mill Wastewaters by Ozonation." Desalination 249(2): 865-869.

El-Din, M.G., and D.W. Smith. 2001. "Maximizing the Enhanced Ozone Oxidation of Kraft Pulp Mill Effluents in an Impinging-Jet Bubble Column." Ozone: Science \& Engineering 23(6): 479-493.

El-Din, M.G., and D.W. Smith. 2002. "Comparing Different Designs and Scales of Bubble Columns for Their Effectiveness in Treating Kraft Pulp Mill Effluents." Ozone: Science \& Engineering 24(5): 307-320.

Ericson, G., and A.K. Larsson. 2000. "DNA Adducts in Perch (Perca fluviatilis) Living in Coastal Water Polluted with Bleached Pulp Mill Effluents." Ecotoxicology and Environmental Safety 46(2): $167-173$.

Esplugas, S., S. Contreras, and O. Ollis. 2004. "Engineering Aspects of Integration of Chemical and Biological Oxidation: Simple Mechanistic Models of Oxidation." Journal of Environmental Engineering 130: 967-974.

Faria, P.C.C., D.C.M. Monteiro, J. Órfão, and M. Pereira. 2009. “Cerium, Manganese and Cobalt Oxides as Catalysts for the Ozonation of Selected Organic Compounds." Chemosphere 74(6): 818-824.

Fontanier, V., J. Albet, S. Baig, and J. Molinier. 2005. "Simulation of Pulp Mill Wastewater Recycling after Tertiary Treatment." Environmental Technology 26(12): 1335-1344.

Fontanier, V., V. Farines, J. Albet, S. Baig, and J. Molinier. 2006. "Study of Catalyzed Ozonation for Advanced Treatment of Pulp and Paper Mill Effluents." Water Research 40: 303-310.

Freire, R.S., L.T. Kubota, and N. Durán. 2001. "Remediation and Toxicity Removal from Kraft E1 Paper Mill Effluent by Ozonization." Environmental Technology 22(8): 897-904.

Garcia, J., and J. Beltran-Heredia. 2008. "Chemical Treatment by Fenton's Reagent Oxidation and Ozonation of Wastewaters from Olive Oil Mill." Journal of Advanced Oxidation Technologies 11(3): 568-572.

Gimeno, O., F. J. Rivas, F. Beltrán, and M. Carbajo (2007). "Photocatalytic Ozonation of Winery Wastewaters." Journal of Agricultural and Food Chemistry 55: 9944-9950.

Gogate, P.R., and A.B. Pandit. 2004a. "A Review of Imperative Technologies for Wastewater Treatment I: Oxidation Technologies at Ambient Conditions." Advances in Environmental Research 8(3-4): 501-551.

Gogate, P.R., and A.B. Pandit. 2004b. "A Review of Imperative Technologies for Wastewater Treatment II: Hybrid Methods." Advances in Environmental Research 8(3-4): 553-597.

Gomec, C.Y., E. Erdim, I. Turan, A. Aydin, and I. Ozturk. 2007. “Advanced Oxidation Treatment of Physico-Chemically Pre-Treated Olive Mill Industry Effluent." Journal of Environmental Science and Health, Part B 42(6): 741-747.

He, K., Y.M. Dong, Z. Li, L. Yin, A. Zhang, and Y. Zheng. 2008. "Catalytic Ozonation of Phenol in Water with Natural Brucite and Magnesia." Journal of Hazardous Materials 159(2-3): 587-592.
Kaindl, N., and P.-A. Liechti. 2008. "Advanced Effluent Treatment with Ozonation and Biofiltration at the Paper Mill SCA-Graphic Laakirchen AG Austria: Design and Operation Experience." Ozone: Science \& Engineering 30(4): 310-317.

Karageorgos, P., A. Coz, M. Charalabaki, N. Kalogerakis, N. Xekoukoulakis, and D. Mantzavinos. 2006. "Ozonation of Weathered Olive Mill Wastewaters.” Journal of Chemical Technology \& Biotechnology 81(9): 1570-1576.

Kasprzyk-Hordern, B., M. Zólek, and J. Nawrocki. 2003. "Catalytic Ozonation and Methods of Enhancing Molecular Ozone Reactions in Water Treatment." Applied Catalysis B: Environmental 46(4): 639-669.

Ko, C.-H., P.-H. Hsieh, M. Chang, J. Chern, S. Chiang, and C. Tzeng. 2009. "Kinetics of Pulp Mill Effluent Treatment by Ozone-Based Processes." Journal of Hazardous Materials 168(2-3): 875-881.

Kreetachat, T., M. Damrongsri, V. Punsuwon, P. Vaitharomsat, C. Chiemchaisri, and C. Chomsurim 2007. "Effects of Ozonation Process on Lignin-Derived Compounds in Pulp And Paper Mill Effluents.” Journal of Hazardous Materials 142(1-2): 250-257.

Lafi, W.K., B. Shannak, M. Al-Shannay, Z. Al-Amber, and M. Al-Hasan. 2009. "Treatment of Olive Mill Wastewater by Combined Advanced Oxidation and Biodegradation." Separation and Purification Technology 70(2): 141-146.

Lan, B.Y., R. Nigmatullin, and G. Puma. 2008a. "Ozonation Kinetics of Cork-Processing Water in a Bubble Column Reactor." Water Research 42(10-11): 2473-2482.

Lan, B.Y., R. Nigmatullin, and G. Puma. 2008b. "Treatment of Industrial Cork Processing Water by Ozonation and Ozone Based Advanced Oxidation Processes $\left(\mathrm{O}_{3} / \mathrm{UV}\right.$ and $\left.\mathrm{O}_{3} / \mathrm{H}_{2} \mathrm{O}_{2}\right)$ in a Bubble Column Reactor." Journal of Advanced Oxidation Technologies 11(1): $135-142$.

Larcher, S., G. Delbés, B. Robaire, and V. Yargeau 2012. "Degradation of 17-ethinylestradiol by ozonation-Identification of the By-products and Assessment of Their Estrogenicity and Toxicity." Environment International 39(1): 66-72.

Legube, B., and N. Karpel Vel Leitner. 1999. "Catalytic Ozonation: A Promising Advanced Oxidation Technology for Water Treatment." Catalysis Today 53(1): 61-72.

Lucas, M.S., J.A. Peres, B. Lan, and G. Puma. 2009. "Ozonation Kinetics of Winery Wastewater in Pilot-Scale Bubble Column Reactor." Water Research 43: 1523-1532.

Lucas, M.S., J.A. Peres, and G. Puma. 2010. "Treatment of Winery Wastewater by Ozone-Based Advanced Oxidation Processes $\left(\mathrm{O}_{3}, \mathrm{O}_{3} / \mathrm{UV}\right.$ and $\left.\mathrm{O}_{3} / \mathrm{UV} / \mathrm{H}_{2} \mathrm{O}_{2}\right)$ in a Pilot-Scale Bubble Column Reactor and Process Economics." Separation and Purification Technology 72(3): 235-241.

Ma, J. and N.J.D. Graham. 2000. "Degradation of Atrazine by ManganeseCatalysed Ozonation-Influence of Radical Scavengers." Water Research 35(15): 3822-3828.

Ma, J., M. Sui, T. Zhang, and C. Guan. 2005. "Effect of pH on MnOx/GAC Catalyzed Ozonation for Degradation of Nitrobenzene." Water Research 39(5): 779-786.

Madaeni, S.S., and Y. Mansourpanah. 2004. "Chemical Cleaning of Reverse Osmosis Membranes Fouled by Whey.” Desalination 161(1): 13-24.

Mantzavinos D., and E. Psilakis. 2004. "Enhancement of Biodegradability of Industrial Wastewaters by Chemical and Oxidation Pre-treatment." Journal of Chemical Technology and Biotechnology 79: 431-454.

Mantzavinos, D., and N. Kalogerakis. 2005. "Treatment of Olive Mill Effluents. Part I. Organic Matter Degradation by Chemical and Biological Processes-An Overview." Environment International 31: 289-295.

Martins, R.C., F.J.R. Abegão, A. Silva, and R. Quinta-Ferreira. 2009. "Integrated Strategy for Treatment of Winery Wastewaters Using Flocculation, Ozonation and Fenton's Oxidation." Journal of Advanced Oxidation Technologies 12(2): 255-264.

Martins, R.C., F.L. Pinto, S. Castro-Silva, and R. Quinta-Ferreira. 2013. "Flocculation, Ozonation and Fenton's Process in the Treatment of Distillery Effluents." Journal of Environmental Engineering 139(1): $110-116$. 
Martins, R.C., and R.M. Quinta-Ferreira. 2009. "Catalytic Ozonation of Phenolic Acids over a Mn-Ce-O Catalyst." Applied Catalysis B: Environmental 90(1-2): 268-277.

Martins, R.C., and R.M. Quinta-Ferreira. 2010. "Final Remediation of Postbiological Treated Milk Whey Wastewater by Ozone." International Journal of Chemical Reactors Engineering 8: A142.

Martins, R.C., and R.M. Quinta-Ferreira. 2011a. "Comparison of Advanced Oxidation Processes (AOPs) based on $\mathrm{O}_{3}$ and $\mathrm{H}_{2} \mathrm{O}_{2}$ for the Remediation of Real Wastewaters." Journal of Advanced Oxidation Technologies 14(2): 282-291.

Martins, R.C., and R.M. Quinta-Ferreira. 2011b. "Phenolic Wastewaters Depuration and Biodegradability Enhancement by Ozone Over Active Catalysts." Desalination 270(1-3): 90-97.

Martins, R.C., A.M.T. Silva, S. Castro-Silva, P. Garção-Nunes, and R. Quinta-Ferreira (2010). "Adopting Strategies to Improve the Efficiency of Ozonation in the Real-Scale Treatment of Olive Oil Mill Wastewaters." Environmental Technology 31(13): 1459-1469.

Medeiros, D.R., E.C. Pires, and M. Monseni. 2008. "Ozone Oxidation of Pulp and Paper Wastewater and its Impact on Molecular Weight Distribution of Organic Matter." Ozone: Science \& Engineering 30(1): 105-110.

Mert, B., T. Yonar, M. Kilç, and K. Kestiloglu. 2010. "Pre-treatment Studies on Olive Mill Effluent Using Physicochemical, Fenton and Fenton-like Oxidation Processes.” Journal Of Hazardous Materials 174: 122-128.

Mills, Andrew, and Soo-Keunlee. 2004. "Semiconductor Photocatalysis." In Advanced Oxidation Processes for Water and Wastewater Treatment, edited by S. Parsons, 137-161. London, UK: IWA Publishing.

Moraes, S., N. Durán, and R. Freire. 2006. "Remediation of Kraft E1 and Black Liquor Effluents by Biological and Chemical Processes." Environmental Chemistry Letters 4(2): 87-91.

Moussavi, G., A. Khavanin, and R. Alizadeh. 2009. "The Investigation of Catalytic Ozonation and Integrated Catalytic Ozonation/Biological Processes for the Removal of Phenol from Saline Wastewaters." Journal of Hazardous Materials 171(1-3): 175-181.

Nawrocki, J., and B. Kasprzyk-Hordern. 2010. "The Efficiency and Mechanisms of Catalytic Ozonation." Applied Catalysis B: Environmental 99(1-2): 27-42.

Owens, J. W., S.M. Swanson, and D. Birkholz. 1994. "Environmental Monitoring of Bleached Kraft Pulp Mill Chlorophenolic Compounds in a Northern Canadian River System.” Chemosphere 29(1): 89-109.

Paraskeva, P., and E. Diamadopoulos. 2006. "Technologies for Olive Mill Wastewater (OMW) Treatment: A Review." Journal of Chemical Technology and Biotechnology 81: 1475-1485.
Pera-Titus, M., V. García-Molina, M. Baños, J. Giménez, and S. Esplugas. 2004. "Degradation of Chlorophenols by Means of Advanced Oxidation Processes: A General Review." Applied Catalysis B: Environmental 47(4): 219-256.

Pérez, M., F. Torrades, X. Domènech, and J. Peral. 2002. "Treatment of Bleaching Kraft Mill Effluents and Polychlorinated Phenolic Compounds with Ozonation." Journal of Chemical Technology \& Biotechnology 77: 891-897.

Pokhrel, D., and T. Viraraghavan. 2004. "Treatment of Pulp and Paper Mill Wastewater-A Review." Science of The Total Environment 333(1-3): 37-58.

Rivas, F., F. Beltrán, and O. Gimeno. 2000a. "Joint Treatment of wastewater from table olive porcessing and urban wastewater. Integrated ozonationAerobic oxidation." Chemical Engineering Technology 25(2): $177-181$.

Rivas, J., F. Beltrán, B. Acedo, and O. Gimeno. 2000b. “Two-Step Wastewater Treatment: Sequential Ozonation - Aerobic Biodegradation." Ozone: Science \& Engineering 22(6): 617-636.

Rueter, J. and R. Johnson. 1995. "The Use of Ozone to Improve Solids Removal During Disinfection." Aquacultural Engineering 14: 123-141.

Sánchez-Polo, M., J. Rivera-Utrilla, and U. Von Gunten. 2006. "Metal-Doped Carbon Aerogels as Catalysts During Ozonation Processes in Aqueous Solutions." Water Research 40: 3375-3384.

Sangave, P.C., P.R. Gogate, and A. Pandit. 2007. "Combination of Ozonation with Conventional Aerobic Oxidation for Distillery Wastewater Treatment." Chemosphere 68(1): 32-41.

Sevimli, M.F. 2005. "Post-Treatment of Pulp and Paper Industry Wastewater by Advanced Oxidation Processes." Ozone: Science \& Engineering 27(1): 37-43.

Staehelin, J. and J. Hoigne. 1982. "Decomposition of Ozone in Water: Rate of Initiation by Hydroxide Ions and Hydrogen Peroxide." Environmental Science \& Technology 16(10): 676-681.

Strong, P.J., and J.E. Burgess. 2008. "Treatment Methods for Wine-Related and Distillery Wastewaters: A Review." Bioremediation Journal 12(2): 70-87.

Zhou, H., and D.W. Smith. 1997. "Effects Of Chemical Reactions On Ozone Mass Transfer In Treating Pulp Mill Wastewater." Water Science \& Technology 32(2/3): 249-260.

Zhou, H., and D.W. Smith. 2000. "Ozonation Dynamics and Its Implication for Off-Gas Ozone Control in Treating Pulp Mill Wastewaters." Ozone: Science \& Engineering 22(1): 31-51. 